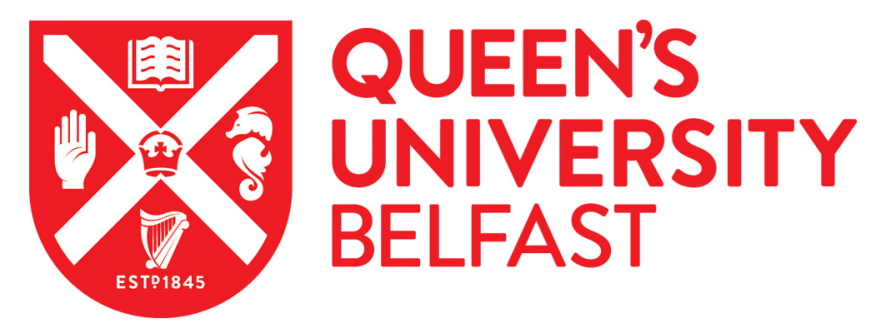

\title{
Factors influencing the compressive strengths of fly ash based geopolymers
}

Soutsos, M., Boyle, A. P., Vinai, R., Hadjierakleous, A., \& Barnett, S. J. (2016). Factors influencing the compressive strengths of fly ash based geopolymers. Construction and Building Materials, 110, 355-368. https://doi.org/10.1016/j.conbuildmat.2015.11.045

\section{Published in:}

Construction and Building Materials

\section{Document Version:}

Peer reviewed version

\section{Queen's University Belfast - Research Portal:}

Link to publication record in Queen's University Belfast Research Portal

\section{Publisher rights}

(c) 2016 Elsevier Ltd. This manuscript version is made available under the CC-BY-NC-ND 4.0 license http://creativecommons.org/licenses/bync-nd/4.0/ which permits distribution and reproduction for non-commercial purposes, provided the author and source are cited.

\section{General rights}

Copyright for the publications made accessible via the Queen's University Belfast Research Portal is retained by the author(s) and / or other copyright owners and it is a condition of accessing these publications that users recognise and abide by the legal requirements associated with these rights.

Take down policy

The Research Portal is Queen's institutional repository that provides access to Queen's research output. Every effort has been made to ensure that content in the Research Portal does not infringe any person's rights, or applicable UK laws. If you discover content in the Research Portal that you believe breaches copyright or violates any law, please contact openaccess@qub.ac.uk. 
1 Factors influencing the compressive strength of fly ash 2 based geopolymers

3 Marios Soutsos ${ }^{1}$, Alan P. Boyle ${ }^{2}$, Raffaele Vinai ${ }^{1}$, Anastasis Hadjierakleous ${ }^{2}$, and Stephanie J. Barnett ${ }^{3}$

$4 \quad{ }^{1}$ School of Planning, Architecture and Civil Engineering, Queen's University Belfast, BT9 5AG, UK

$5 \quad{ }^{2}$ School of Environmental Sciences, University of Liverpool, L69 3GP, UK

$6 \quad{ }^{3}$ School of Civil Engineering and Surveying, University of Portsmouth, PO1 2UP, UK

\section{Abstract}

Several factors affecting the reactivity of fly ash (FA) as a precursor for geopolymer concrete have been investigated. These include physical and chemical properties of various FA sources, inclusion of ground granulated blast furnace slag (ggbs), chemical activator dosages and curing temperature. Alkali-activated FA was found to require elevated curing temperatures and high alkali concentrations. A mixture of sodium hydroxide and sodium silicate was used and this was shown to result in high strengths, as high as $70 \mathrm{MPa}$ at 28 days. The presence of silicates in solution was found to be an important parameter affecting strength. Detailed physical and chemical characterisation was carried out on thirteen FA sources from the UK. The most important factor affecting the reactivity was found to be the particle size of FA. The loss on ignition (LOI) and the amorphous content are also important parameters that need to be considered for the selection of FA for use in geopolymer concrete. The partial replacement of FA with ggbs was found to be beneficial in not only avoiding the need for elevated curing temperatures but also in improving compressive strengths. Microstructural characterisation with scanning electron microscope (SEM) coupled with energy dispersive Xray spectroscopy (EDS) was performed on FA/ggbs pastes. The reaction product of FA and ggbs in these binary systems was calcium aluminium silicate hydrate gel (C-A-S-H) with inclusion of $\mathrm{Na}$ in the structure.

Keywords: geopolymer, alkali activated material, fly ash, slag, structural characterisation, mechanical properties, alkali dosages optimisation

\section{Introduction}

The term "geopolymer" was introduced by Davidovits in the 1970s referring to alkali-activated metakaolin [1]. It has since been used for a range of synthetic low-calcium aluminosilicate polymeric materials, as a sub-range of a more general definition which is alkali-activated binders ( $A A B)$. Although the initial studies were focused 
on geological materials such as metakaolin activated with siliceous solutions [2-6], the potential of using other synthetic reactive aluminosilicate materials activated with a range of concentrated alkaline solutions became apparent $[1,7-8]$

AABs have been studied for the last 40 years [9] and have applications in ceramics, hazardous waste containment, fire-resistant construction materials and refractories [10, 11]. One of the most interesting applications is their use as a cement-free binder that can replace Portland cement-based pastes in construction materials such as concrete and mortar products [12].

Geopolymers can provide a desirable alternative to Portland cement (PC) binders, not only for the environmental benefits arising from the avoidance of $\mathrm{CO}_{2}$ emissions associated with $\mathrm{PC}$ production, but also in terms of their performance and durability, where such properties are not only equivalent, but often better than those achieved with PC. The nature of the reactions occurring in geopolymerisation can be summarized in three basic steps [13]:

1. Dissolution of the aluminosilicate solids: aluminosilicates in the pozzolanic solid are dissolved by alkaline hydrolysis in the high $\mathrm{pH}$ solution of the concentrated alkaline activator. This forms a solution of silicate, aluminate and aluminosilicate species.

2. Gel Formation: species released by dissolution are held in the aqueous phase, which may also contain silicate present from the activating solution. This supersaturated aluminosilicate solution forms a gel as oligomers form long chains and networks. This stage releases complexing water, which resides in pores.

3. Polycondensation: the gel species continue to rearrange and reorganize, forming an increasingly larger network. This results in the three-dimensional aluminosilicate network of the geopolymer binder.

These processes often occur contemporaneously throughout the mixture, rather than in a linear time series.

The dense inorganic polymer that forms the geopolymer binder thus provides physicochemical features that may be superior to Portland cement systems, i.e.:

- $\quad$ The interconnected framework gives geopolymers high compressive strengths $[13,14]$. 
- Due to the microstructure of the reaction products, geopolymer and AAB can show good to very good resistance to chemical degradation (sulphate attack, acid attack, seawater attack) [9].

- The geopolymer matrix shows high thermal and fire resistance up to $1000-1200^{\circ} \mathrm{C}[14]$.

- Geopolymers may exhibit rapid setting without long term deterioration of strength [13].

Of particular interest is the selection of precursor aluminosilicate materials that arise from waste-streams or as by-product pozzolans, which are readily available from existing industries [15]. These include fly ash (FA) and ground granulated blast furnace slag (ggbs). Although ggbs has a relatively high demand from an existing market-base, and an associated relatively high value, perhaps equivalent to that of Portland cement, wastestream pozzolans such as FA are not fully recycled into value added products, and excesses are stockpiled or landfilled.

Reaction mechanisms responsible for the creation of an amorphous gel from fly ash are complex and still not fully understood [9]. A wide variability in chemical dosages can be found in the scientific literature related to the activation of FA systems [16], indicating that optimum proportions of alkali species (hydroxides and silicates) in the activating solution, as well as quantity of alkali per binder mass, still need to be investigated to improve our understanding of the reaction mechanisms. Curing parameters such as curing temperature and stand time, i.e. the time elapsed before the start of high temperature curing, play an important role in the full development of the reaction products. Information available in technical literature is relatively limited, and thus a systematic investigation is still needed for determining optimum curing conditions.

Fly ashes are not a "standard product" as their physical and chemical properties vary considerably not only from source to source but also over time from the same power station [9]. The Department of Energy and Climate Change in its digest of UK energy statistics [17] quoted 14 power stations operational at the end of May 2014 that were using coal or coal mixed (gas/oil) fuel, representing $26 \%$ of total electricity generated. Heath et al. [18] reported that FA production in UK is estimated at about $6 \cdot 10^{6} \mathrm{t}$ per annum, half of which is sent to landfill, whereas about $114 \cdot 10^{6}$ t of FA is available in stockpiles. The potential availability for FA-based geopolymer concrete production is therefore significant in the UK, although the suitability of such available ashes has never been investigated in a comprehensive manner. 
FA-based geopolymers need an external energy source in the form of thermal curing for the reaction to take place. This can be a drawback for the upscaling of the process to the industrial level. On the other hand, Carich slags such as ggbs react at room temperature since their reaction, i.e. the hydration of Ca species and the creation of a calcium-aluminium-silicate-hydrate (C-A-S-H) gel, is different from low-calcium precursors. Moreover, the reaction develops at a very rapid pace, often resulting in a very short initial setting time. The blend of FA/ggbs for achieving a system reacting at room temperature without rapid setting would suit most concrete applications. Relatively few publications are available in the literature [19-23] and thus further investigations are needed to provide a better insight into the properties and performance of such binary systems.

The work described here aimed to study (a) the effect of curing procedure and activator dosages on the strength development of FA-based mortar, (b) the influence of physical and chemical properties of 13 FA sources obtained from 8 UK power stations, (c) the effect of partial substitution with ggbs on the compressive strength development and microstructure of the reacted mortar.

\section{Materials and Methods}

The chemical composition of 13 FA sources from the UK were assessed by X-ray fluorescence (XRF) at the University of Leicester and these are shown in Table 1. Loss on Ignition (LOI) was determined on powders previously dried overnight at $105^{\circ} \mathrm{C}$. Samples were ignited for 90 minutes @ $950^{\circ} \mathrm{C}$ in air ventilated electric muffle furnace and the mass loss was then calculated. Mineralogical characterisation was carried out by X-ray diffraction (XRD) using a PANalytical X'Pert PRO X-ray diffractometer, equipped with programmable anti scatter slits, rotating sample stage and the X'Celerator Real Time Multiple Strip X'lerator Detector. The incident X-rays were from a Copper K $\alpha$ X-ray source, running at $40 \mathrm{kV}$ and $40 \mathrm{~mA}$ and obtained spectra are shown in Figure 1. Quartz $\left(\mathrm{SiO}_{2}\right)$ and mullite $\left(3 \mathrm{Al}_{2} \mathrm{O}_{3} \cdot 2 \mathrm{SiO}_{2}\right)$ were the main crystalline components identified. The amorphous content (visible as the broad hump in the background of the XRD pattern centred at $20-30^{\circ} 2 \theta$ ) was quantified by adding an internal standard (corundum) and performing a Rietveld method-based analysis (results are shown in Table 2). Laser diffraction grain size distribution was used to assess the particle size distribution of all the investigated sources of FA. Results are shown in Figure 2, where the 13 FA samples are divided in three classes according to their $D_{50}$ value (shown in Table 2): low $\left(D_{50}<25 \mu \mathrm{m}\right)$, medium $\left(26<D_{50}<\right.$ 

activator dosages.

109 Table 1. Elemental composition (from XRF) of the 13 FA sources investigated and of the ggbs utilised. Results 110 quoted as component oxide (and LOI) weight percent.

\begin{tabular}{|c|c|c|c|c|c|c|c|c|c|c|c|c|c|c|}
\hline \multirow{2}{*}{ Oxide } & \multicolumn{13}{|c|}{ FA sources } & \multirow[b]{2}{*}{ ggbs } \\
\hline & $\bar{A}$ & B & C & $\mathrm{D}$ & $\mathrm{E}$ & $\mathrm{F}$ & $\bar{G}$ & $\mathrm{H}$ & $\mathrm{I}$ & $\mathrm{J}$ & $\mathrm{K}$ & $\mathrm{L}$ & $M$ & \\
\hline $\mathrm{SiO}_{2}$ & 51.52 & 48.90 & 44.58 & 49.28 & 48.48 & 56.40 & 51.32 & 43.38 & 51.33 & 51.05 & 51.23 & 49.90 & 51.76 & 35.82 \\
\hline $\mathrm{TiO}_{2}$ & 0.97 & 0.95 & 0.91 & 0.95 & 1.08 & 0.92 & 1.03 & 0.84 & 0.97 & 1.02 & 0.80 & 1.02 & 0.89 & 0.00 \\
\hline $\mathrm{Al}_{2} \mathrm{O}_{3}$ & 23.58 & 23.51 & 21.94 & 23.43 & 24.86 & 22.14 & 24.85 & 23.63 & 24.12 & 25.06 & 18.37 & 27.12 & 24.51 & 13.00 \\
\hline $\mathrm{Fe}_{2} \mathrm{O}_{3}$ & 7.11 & 12.36 & 10.59 & 10.61 & 9.49 & 6.63 & 7.24 & 6.56 & 8.51 & 8.60 & 4.55 & 7.38 & 8.58 & 0.53 \\
\hline $\mathrm{Mn}_{3} \mathrm{O}_{4}$ & 0.07 & 0.15 & 0.13 & 0.10 & 0.12 & 0.07 & 0.09 & 0.13 & 0.11 & 0.09 & 0.06 & 0.08 & 0.15 & 0.51 \\
\hline $\mathrm{MgO}$ & 1.75 & 1.97 & 1.93 & 1.73 & 2.22 & 1.59 & 1.56 & 1.36 & 1.92 & 1.79 & 1.36 & 1.45 & 1.92 & 8.00 \\
\hline $\mathrm{CaO}$ & 3.86 & 3.41 & 3.61 & 2.68 & 4.53 & 2.97 & 2.88 & 2.83 & 2.75 & 2.37 & 2.55 & 2.25 & 3.78 & 40.62 \\
\hline $\mathrm{Na}_{2} \mathrm{O}$ & 0.74 & 0.93 & 0.83 & 1.55 & 0.98 & 0.97 & 0.57 & 0.79 & 0.80 & 0.98 & 0.45 & 0.67 & 0.49 & 0.00 \\
\hline $\mathrm{K}_{2} \mathrm{O}$ & 2.42 & 3.26 & 2.61 & 3.57 & 2.60 & 1.91 & 1.63 & 1.39 & 3.61 & 3.47 & 1.60 & 3.23 & 2.87 & 0.00 \\
\hline $\mathrm{P}_{2} \mathrm{O}_{5}$ & 0.37 & 0.41 & 0.38 & 0.32 & 0.45 & 0.58 & 0.75 & 0.72 & 0.25 & 0.33 & 0.61 & 0.33 & 0.25 & 0.00 \\
\hline $\mathrm{SO}_{3}$ & 0.84 & 0.49 & 0.59 & 0.47 & 0.63 & 0.47 & 0.41 & 0.28 & 0.49 & 0.32 & 0.39 & 0.18 & 0.32 & 0.05 \\
\hline $\mathrm{V}_{2} \mathrm{O}_{5}$ & 0.09 & 0.06 & 0.06 & 0.07 & 0.07 & 0.05 & 0.06 & 0.03 & 0.06 & 0.07 & 0.03 & 0.06 & 0.05 & 0.00 \\
\hline $\mathrm{Cr}_{2} \mathrm{O}_{3}$ & 0.02 & 0.02 & 0.02 & 0.02 & 0.03 & 0.02 & 0.03 & 0.01 & 0.02 & 0.03 & 0.01 & 0.02 & 0.02 & 0.00 \\
\hline SrO & 0.10 & 0.08 & 0.08 & 0.07 & 0.15 & 0.12 & 0.13 & 0.15 & 0.06 & 0.07 & 0.15 & 0.07 & 0.05 & 0.00 \\
\hline $\mathrm{ZrO}_{2}$ & 0.00 & 0.07 & 0.06 & 0.07 & 0.07 & 0.07 & 0.07 & 0.11 & 0.06 & 0.07 & 0.07 & 0.06 & 0.06 & 0.00 \\
\hline $\mathrm{BaO}$ & 0.14 & 0.14 & 0.14 & 0.14 & 0.20 & 0.20 & 0.18 & 0.26 & 0.15 & 0.16 & 0.22 & 0.21 & 0.18 & 0.00 \\
\hline $\mathrm{NiO}$ & 0.02 & 0.02 & 0.02 & 0.02 & 0.02 & 0.02 & 0.02 & 0.01 & 0.01 & 0.02 & 0.01 & 0.02 & 0.01 & 0.00 \\
\hline $\mathrm{CuO}$ & 0.02 & 0.02 & 0.02 & 0.02 & 0.02 & 0.01 & 0.02 & 0.00 & 0.01 & 0.02 & 0.00 & 0.02 & 0.01 & 0.00 \\
\hline $\mathrm{ZnO}$ & 0.04 & 0.04 & 0.03 & 0.04 & 0.06 & 0.04 & 0.06 & 0.02 & 0.04 & 0.04 & 0.01 & 0.06 & 0.01 & 0.00 \\
\hline $\mathrm{PbO}$ & 0.03 & 0.04 & 0.03 & 0.05 & 0.04 & 0.05 & 0.06 & 0.02 & 0.04 & 0.04 & 0.02 & 0.05 & 0.02 & 0.00 \\
\hline LOI & 4.92 & 3.60 & 11.17 & 5.01 & 4.07 & 4.61 & 6.99 & 17.40 & 4.62 & 4.53 & 17.28 & 5.20 & 4.28 & 0.66 \\
\hline Total & 98.61 & 100.43 & 99.73 & 100.20 & 100.17 & 99.84 & 99.95 & 99.92 & 99.93 & 100.13 & 99.77 & 99.38 & 100.21 & 99.19 \\
\hline
\end{tabular}

111 

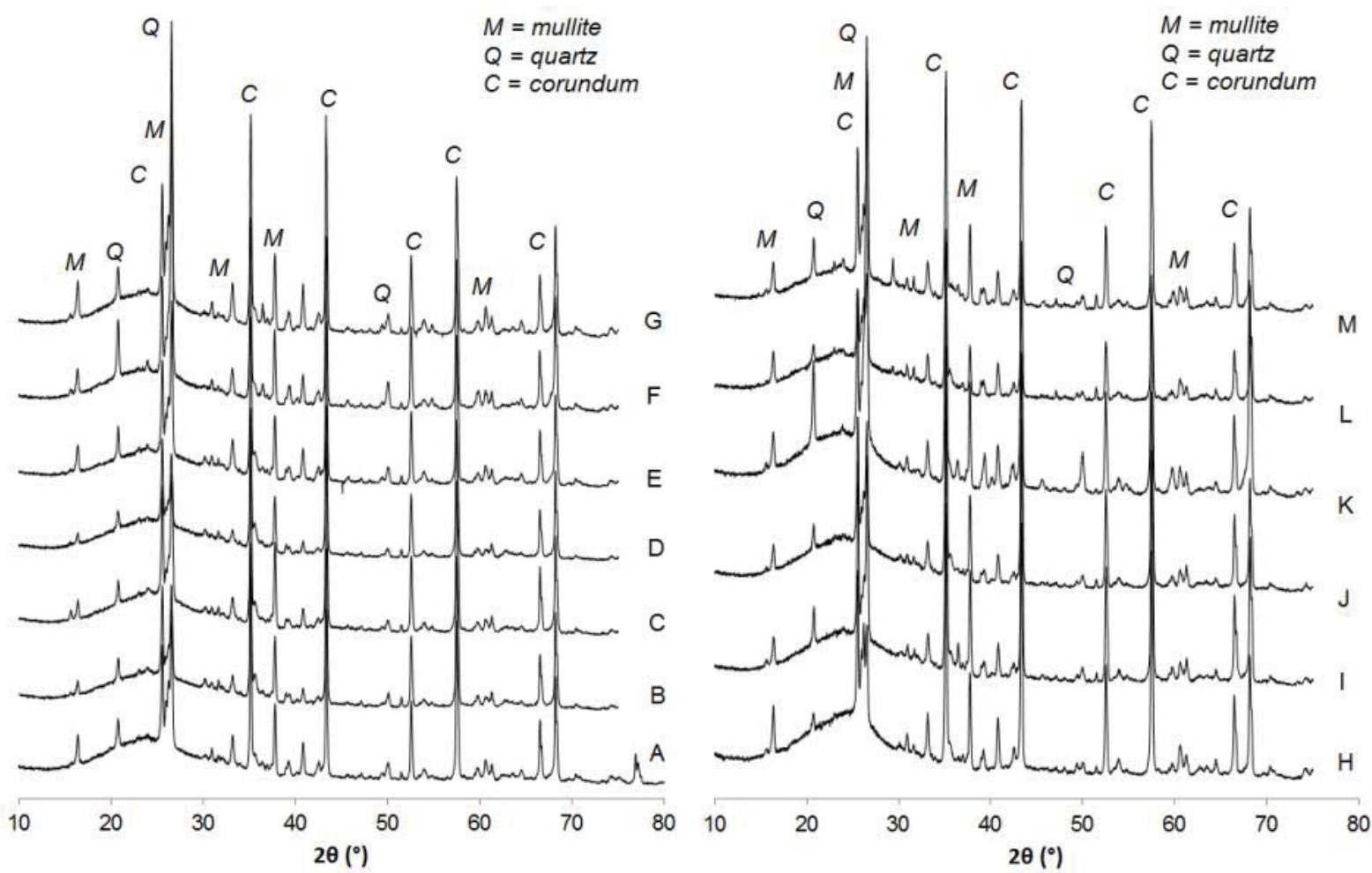

Figure 1. XRD spectra for the 13 investigated FA sources. Labels A-M equate to labels A-M in Table 1.

Table 2. Physical properties of the 13 FA sources investigated.

\begin{tabular}{|c|c|c|c|c|c|c|c|c|c|c|c|c|c|}
\hline & A & B & C & $\mathrm{D}$ & $\mathrm{E}$ & $\mathrm{F}$ & G & H & 1 & J & K & L & $M$ \\
\hline $\mathrm{D}_{50}(\mu \mathrm{m})$ & 23.8 & 29.2 & 41.6 & 27.3 & 20.2 & 26.5 & 30.5 & 37.3 & 32.9 & 17.3 & 34.7 & 13.2 & 91.2 \\
\hline $\mathrm{Am} . \%^{1}$ & 82 & 89 & 86 & 90 & 79 & 76 & 75 & 83 & 86 & 87 & 75 & 79 & 81 \\
\hline$\% 45 \mu \mathrm{m}^{2}$ & 66.9 & 63.2 & 51.0 & 69.0 & 77.6 & 62.4 & 61.0 & 54.9 & 57.3 & 76.4 & 56.4 & 84.8 & 18.9 \\
\hline
\end{tabular}

$117{ }^{1}$ Amorphous content from XRD Rietveld method quantification

$118{ }^{2}$ Volume percentages passing at $45 \mu \mathrm{m}$

119

120

121

122 

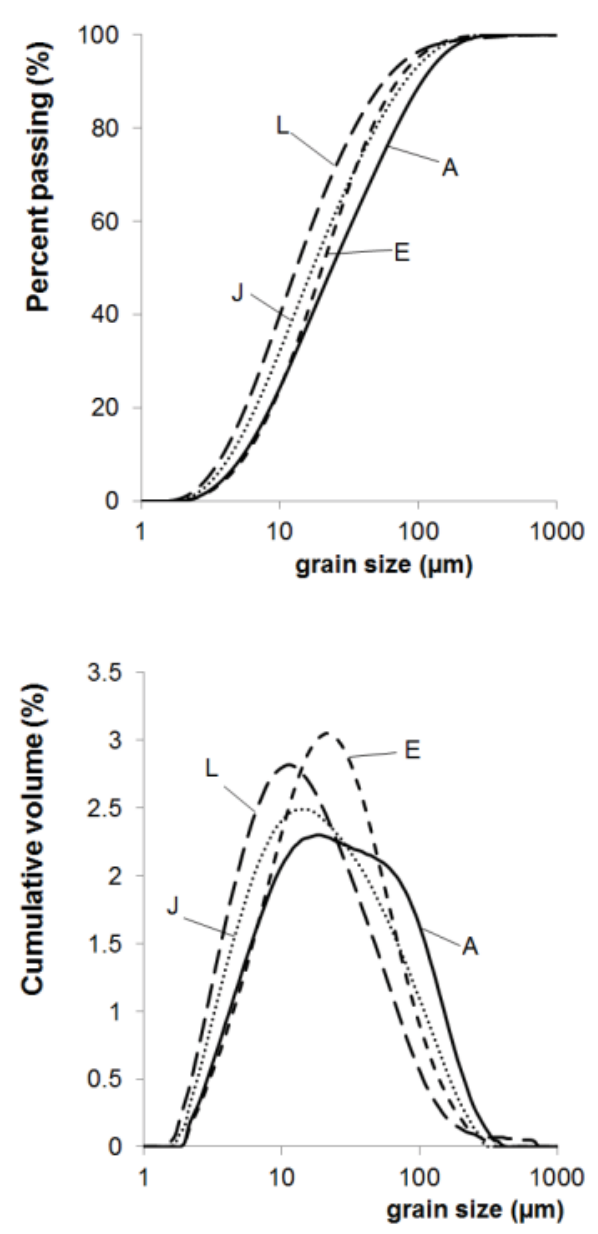

123
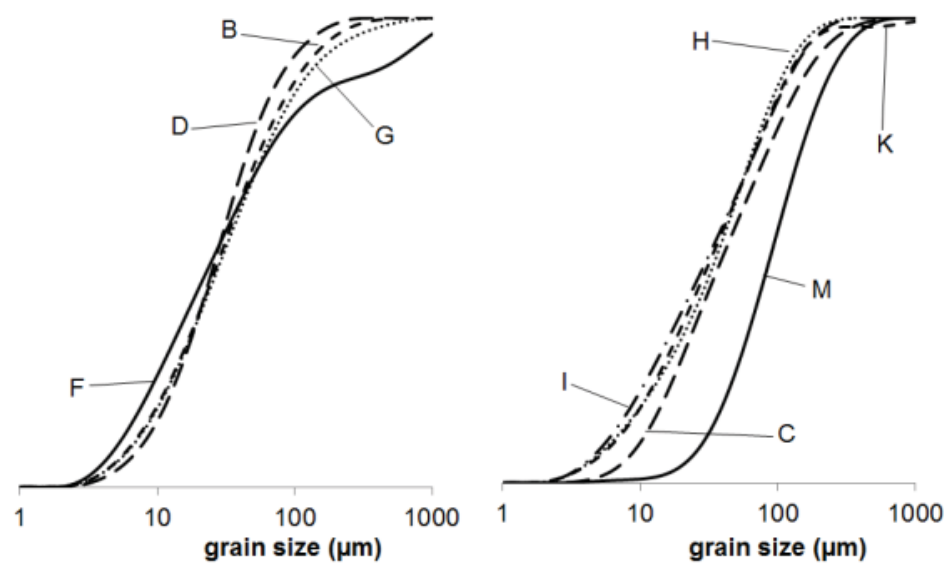

(a) \% passing
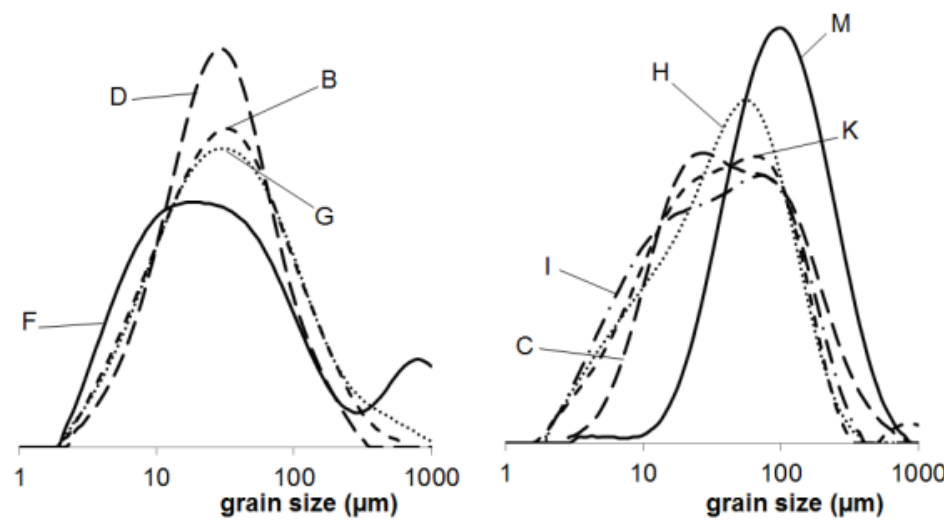

(b) Cumulate volume

Figure 2. Grain size distribution curves for the 13 investigated FA sources. Labels A-M equate to those in Fig. 1 and Table 1.

Ground granulated blast furnace slag was supplied by Hanson Ltd. The chemical composition was obtained by XRF analysis and detected oxides are shown in Table 1.

Commercially available alkalis were used. Laboratory grade sodium hydroxide $(\mathrm{NaOH})$ in solid form was dissolved in water at the required dosage, whereas sodium silicate was supplied as a solution with the following composition: $12.8 \% \mathrm{Na}_{2} \mathrm{O}, 25.5 \% \mathrm{SiO}_{2}$ and $61.7 \% \mathrm{H}_{2} \mathrm{O}$. The alkali dosage $(\mathrm{M}+)$ was defined as the percentage mass ratio of total sodium oxide $\left(\mathrm{Na}_{2} \mathrm{O}\right)$ in the activating solution to the binder. The alkali modulus (AM) was defined as the mass ratio of sodium oxide to silica in the activating solution. $M+$ was from $7.5 \%$ to $15 \%$, whereas $A M$ was from 0.5 to $\infty$ for the first series of experiments. The 0.5 corresponds to an all sodium silicate solution and $\infty$ corresponds to an all sodium hydroxide solution. A range of dosages were used to find which values gave the maximum strength. These values were then used in subsequent experiments 
investigating the influence of physical and chemical properties of different FA sources. For the assessment of the effect of partial substitution with ggbs on the compressive strength development and microstructure of the reacted mortar, AM was fixed at 1.25 , whilst the $M+$ was varied from $3 \%$ to $10 \%$.

The water/solids ratio was defined as the ratio between total mass of water (i.e. added water mass + water mass in the alkali solutions) and the total solid mass (i.e. mass of binder + mass of alkali solids). This ratio was kept constant at 0.37 , except when the mixture was found to be of very low consistency after mixing. In such cases, additional water was added until a workable mixture was obtained. This was generally only necessary for $100 \%$ ggbs binder.

Well-graded, rounded quartz sand sized $0 / 5 \mathrm{~mm}$ was used for preparation of mortars. The adopted sand/binder mass ratio was equal to 2.75. A 5 I planetary mixer was used. Binder and sand were placed in the mixer bowl and mixed for one minute. The alkali solution was then added and the material was mixed for a further 9 minutes. A flow table test was then performed according to BS EN 12350-5 [24]. Mixing was continued for a further 5 minutes, giving a total mixing time of 15 minutes. The mortar was then transferred to $50 \mathrm{~mm}$ cube moulds and compacted on a vibrating table for 60 seconds. Moulds were then sealed by wrapping in polyethylene film.

In the first series of mixes, four sets of curing conditions were used: (a) 1 hour at $20^{\circ} \mathrm{C}$ followed by curing at $50^{\circ} \mathrm{C}$; (b) 24 hours at $20^{\circ} \mathrm{C}$ followed by curing at $50^{\circ} \mathrm{C}$; (c) 1 hour at $20^{\circ} \mathrm{C}$ followed by curing at $70^{\circ} \mathrm{C}$; (d) 24 hours at $20^{\circ} \mathrm{C}$ followed by curing at $70^{\circ} \mathrm{C}$. One cube from each curing regime was tested in compression after 1 , 3 and 7 days curing, with two cubes from each curing regime tested at 28 days. Stand time and oven curing time were included for the computation of the total curing time. Some of the mixes were replicated to confirm the reliability of the results. A $300 \mathrm{kN}$ capacity compression testing machine was used for all testing with a loading rate of $0.8 \mathrm{kN} / \mathrm{s}$.

In the second series of mixes, two sets of curing conditions were used: (a) 1 hour at $20^{\circ} \mathrm{C}$ followed by curing at $50^{\circ} \mathrm{C}$ and (b) 1 hour at $20^{\circ} \mathrm{C}$ followed by curing at $70^{\circ} \mathrm{C}$. Same procedure as in the first series of mixes was used for determining the compressive strength. 
In the third series of mixes, two sets of curing conditions were used: (a) 1 hour at $20^{\circ} \mathrm{C}$ followed by curing at $70^{\circ} \mathrm{C}$ and (b) curing at $20^{\circ} \mathrm{C}$ (ambient/room temperature). Two replica cubes from each curing regime were tested in compression at 1,7 and 28 days.

X-ray diffraction on raw materials and reacted pastes was carried out with Panalytical X'Pert Pro MPD

Diffractometer with $X^{\prime}$ Celerator detector scanned the range of $4-70^{\circ} 2 \theta$, using $\mathrm{Cu}$ K- $\alpha$ radiation. Zincite was used as internal standard. HighScore Plus software was used to obtain semi-quantitative mineral weight percentages.

Images for microstructural analysis were acquired with either a Philips XL30 Scanning Electron Microscope equipped with an Oxford Instruments INCA energy dispersive X-ray spectroscopy (EDS) system or a Hitachi TM300 SEM equipped with a Bruker Quantax 70 EDS systems. The EDS systems allow the collection of chemical information for spots and areas in the samples. The samples comprised broken pieces $(\sim 5.0 \times 5.0 \times$ $2.5 \mathrm{~mm}$ ) of hardened paste mounted onto aluminium stubs using epoxy adhesive, orienting the fractured surface in a convenient position towards the SEM beam also bearing in mind the location of the EDS detector. Samples were coated with a thin gold-palladium layer to provide a conductive pathway to prevent surface electrical charging.

\section{Results and discussion}

\subsection{Effect of curing procedure and activator dosages on strength development}

Twenty-four combinations of $\mathrm{M}+$ and $\mathrm{AM}$ were investigated for each of the four curing regimes, for a total number of 96 different series of mixes. The effects of stand time (i.e. the time elapsed between the mixing and the start of the curing in oven, during which the process of dissolution and gelation of aluminosilicates species takes place), curing temperature, and activator dosage were investigated by determining the compressive strength development. Obtained compressive strengths are shown in Table 3. 

chemical dosages. Results are expressed in MPa.

\begin{tabular}{|c|c|c|c|c|c|c|c|c|c|c|c|c|c|c|c|c|c|}
\hline \multirow[t]{2}{*}{ AM } & \multirow{2}{*}{$\begin{array}{l}\text { Curing } \\
\text { time } \\
\text { (days) }\end{array}$} & \multicolumn{2}{|c|}{$\begin{array}{l}1 \mathrm{~h} \text { stand } \\
\text { time }\end{array}$} & \multicolumn{2}{|c|}{$50^{\circ}$ curing } & \multicolumn{2}{|c|}{$\begin{array}{l}24 \mathrm{~h} \text { stand } \\
\text { time }\end{array}$} & \multicolumn{2}{|c|}{$50^{\circ}$ curing } & \multicolumn{2}{|c|}{$\begin{array}{l}1 \mathrm{~h} \text { stand } \\
\text { time }\end{array}$} & \multicolumn{2}{|c|}{$70^{\circ}$ curing } & \multicolumn{2}{|c|}{$\begin{array}{l}24 \mathrm{~h} \text { stand } \\
\text { time }\end{array}$} & \multicolumn{2}{|c|}{$70^{\circ}$ curing } \\
\hline & & 7.5 & 10 & 12.5 & 15 & 7.5 & 10 & 12.5 & 15 & 7.5 & 10 & 12.5 & 15 & 7.5 & 10 & 12.5 & 15 \\
\hline \multirow{5}{*}{ นกำ } & 1 & & 5.4 & & & & & & & 9.7 & 10.1 & & & & & & \\
\hline & 3 & & 20.2 & & & 14.0 & 11.3 & & & 13.0 & 14.8 & & & 13.6 & 14.7 & & \\
\hline & 7 & 17.3 & 28.3 & & & 17.9 & 24.2 & & & 11.7 & 13.9 & & & 13.7 & 16.4 & & \\
\hline & 28 & & 23.6 & & & 17.5 & 18.2 & & & 13.0 & 14.4 & & & 12.7 & 15.8 & & \\
\hline & 28 & & 21.0 & & & 16.0 & 20.4 & & & 13.3 & 14.6 & & & 14.5 & 18.2 & & \\
\hline \multirow{11}{*}{$-r$} & & 8.5 & 7.5 & 7.7 & 3.9 & & & & & 25.4 & 32.3 & 36.6 & 36.4 & & & & \\
\hline & 1 & & & & 3.5 & & & & & & & & 40.7 & & & & \\
\hline & & & & & 3.9 & & & & & & & & 41.3 & & & & \\
\hline & & 15.7 & 17.4 & 27.5 & 26.9 & 14.6 & 15.8 & 22.4 & 19.4 & 40.9 & 47.4 & 49.5 & 53.5 & 38.1 & 38.3 & 45.0 & 56.1 \\
\hline & 3 & & & & 27.6 & & & & 18.9 & & & & 57.5 & & & & 55.6 \\
\hline & & 19.1 & 15.7 & 24.4 & 33.8 & 20.7 & 13.6 & 24.5 & 39.0 & 43.6 & 44.8 & 51.9 & 52.0 & 42.5 & 44.1 & 47.1 & 54.3 \\
\hline & 7 & & & & 32.2 & & & & 39.3 & & & & 51.2 & & & & 57.7 \\
\hline & & 23.9 & 12.4 & 24.0 & 28.2 & 24.0 & 13.3 & 23.4 & 28.7 & 41.5 & 46.0 & 51.6 & 50.8 & 44.3 & 41.0 & 49.9 & 49.4 \\
\hline & & 22.8 & 16.9 & 24.4 & 27.6 & 22.9 & 16.5 & 23.9 & 29.8 & 43.1 & 45.8 & 48.6 & 51.3 & 44.1 & 43.9 & 48.3 & 52.2 \\
\hline & 28 & & & & 27.7 & & & & 30.0 & & & & 54.9 & & & & 53.9 \\
\hline & & & & & 28.3 & & & & 28.0 & & & & 51.0 & & & & 52.4 \\
\hline \multirow{10}{*}{$\stackrel{\mathscr{n}}{\sim}$} & & 6.6 & 7.7 & 5.9 & 2.6 & & & & & 23.0 & 32.4 & 39.3 & 40.6 & & & & \\
\hline & 1 & & & & 1.6 & & & & & & & & 30.4 & & & & \\
\hline & & 17.0 & 16.3 & 25.7 & 21.4 & 13.4 & 15.1 & 23.1 & 14.1 & 37.8 & 49.3 & 63.9 & 63.4 & 37.6 & 42.1 & 57.8 & 44.6 \\
\hline & 3 & & & & 20.4 & & & & 13.3 & & & & 55.7 & & & 59.2 & \\
\hline & & 21.8 & 18.2 & 24.4 & 24.6 & 22.1 & 15.8 & 24.5 & 25.1 & 37.1 & 48.6 & 63.0 & 53.3 & 43.6 & 50.4 & 69.5 & 46.9 \\
\hline & 7 & & & & 24.9 & & & & 29.4 & & & & 48.8 & & & 51.2 & \\
\hline & & 23.5 & 19.6 & 23.4 & 22.9 & 23.2 & 18.6 & 23.1 & 24.4 & 38.3 & 49.4 & 59.5 & 55.5 & 42.3 & 46.7 & 64.4 & 48.1 \\
\hline & & 24.8 & 17.7 & 24.5 & 23.8 & 24.6 & 17.3 & 22.4 & 24.1 & 38.5 & 51.7 & 62.2 & 57.5 & 42.7 & 48.4 & 67.1 & 44.1 \\
\hline & 28 & & & & 22.2 & & & & 24.8 & & & & 54.7 & & & 66.1 & \\
\hline & & & & & 23.4 & & & & & & & & 54.7 & & & 56.2 & \\
\hline & 1 & 4.2 & 4.9 & 4.8 & 2.2 & & & & & 18.3 & 26.8 & 38.9 & 39.1 & & & & \\
\hline & 3 & 15.7 & 17.3 & 21.7 & 17.8 & 13.7 & 14.5 & 17.3 & 12.4 & 30.1 & 37.6 & 64.5 & 63.0 & 25.1 & 43.5 & 51.9 & 41.4 \\
\hline$\stackrel{n}{\sim}$ & 7 & 20.5 & 20.5 & 29.5 & 23.1 & 22.7 & 17.5 & 24.0 & 23 & 29.5 & 39.9 & 58.2 & 57.1 & 26.9 & 44.3 & 60.8 & 45.1 \\
\hline & & 23.9 & 22.7 & 21.9 & 23.5 & 24.3 & 19.6 & 24.8 & 25.5 & 27.7 & 44.6 & 61.3 & 57.2 & 37.4 & 46.3 & 61.6 & 49.9 \\
\hline & 28 & 23.1 & 22.9 & 22.4 & 22.1 & & 18.9 & 24.5 & 21.5 & 28.3 & 42.2 & 62.0 & 59.4 & 30.3 & 42.3 & 61.7 & 49.1 \\
\hline & 1 & 2.3 & 3.1 & 3.5 & 1.7 & & & & & 11.4 & 21.6 & 34.7 & 29.9 & & & & \\
\hline & 3 & 8.9 & 15.4 & 23.4 & 19.2 & 8.9 & 12.0 & 13.9 & 10.3 & 17.3 & 27.3 & 57.0 & 28.3 & 18.9 & 32.3 & 59.8 & 44.3 \\
\hline & J & & & & 10.0 & & & & & & & & & & & & \\
\hline & 7 & 13.7 & 24.5 & 24.1 & 22.9 & 14.1 & 24.1 & 27.2 & 37.5 & 15.7 & 32.6 & 57.5 & 24.2 & 20.0 & 35.6 & 55.9 & 55.2 \\
\hline$\sim$ & 1 & 14.1 & & & 34.1 & 14.4 & & & 29.8 & 17.9 & & & 37.4 & 19.6 & & & 43.0 \\
\hline & & 15.4 & 24.8 & 23.3 & 24.5 & 16.2 & 27.6 & 23.6 & 36.2 & 17.9 & 35.8 & 57.9 & 24.3 & 19.2 & 37.1 & 58.3 & 53.6 \\
\hline & & 14.2 & 27.4 & 25.1 & 23.4 & 14.3 & 26.3 & 23.6 & 32.8 & 18.2 & 33.1 & 54.7 & 27.5 & 19.7 & 39.0 & 58.2 & 50.6 \\
\hline & 28 & & & & 37.0 & & & & 42.5 & & & & 38.9 & & & & 46.9 \\
\hline & & & & & 27.1 & & & & 35.3 & & & & 37.5 & & & & 46.1 \\
\hline & 1 & & 1.0 & 0.0 & & & & & & 6.4 & 14.3 & 16.5 & 9.9 & & & & \\
\hline & 3 & 7.8 & 12.6 & 7.5 & 3.1 & 4.5 & 3.9 & 19.8 & 1.5 & 10.3 & 23.1 & 24.8 & 22.5 & 11.9 & 22.8 & 37.5 & 35.5 \\
\hline 8 & 7 & 9.8 & 14.5 & 19.6 & 21.4 & 9.1 & 18.1 & 21.8 & 25.7 & 11.6 & 22.6 & 28.1 & 25.7 & 12.9 & 23.1 & 27.8 & 26.4 \\
\hline & & 10.7 & 17.0 & 19.4 & 18.1 & 10.7 & 16.9 & 19.3 & 24.9 & 13.4 & 24.8 & 31.9 & 26.0 & 14.2 & 27.0 & 33.2 & 35.8 \\
\hline & 28 & 10.8 & 17.7 & 17.4 & 15.9 & 10.6 & 17.8 & 20.5 & 25.7 & 13.5 & 24.2 & 31.9 & 26.1 & 14.0 & 24.4 & 36.4 & 38.1 \\
\hline
\end{tabular}

188

$189 \quad$ 3.1.1 Effect of stand time at $20^{\circ} \mathrm{C}$

190 In order to assess the effect of the time for dissolution and gelation at room temperature on ultimate strength,

191 half the samples in each mix were left to stand for 1 hour prior to oven curing and half for 24 hours. Figure 3

192 shows the results for the 28 -day tests for the all mixes cured at $70^{\circ} \mathrm{C}$. It was observed that compressive 
strength increased from day 1 to day 7, and then the strength gain was small, with 7-day and 28-day strengths being often similar. For this reason, it was considered appropriate to compare 28 -day strengths of $1 \mathrm{~h}$ and $24 \mathrm{~h}$ stand time samples, as the difference in curing time in the oven ( 27 vs. 28 days) can be considered negligible. In general, the difference in strength at 28 days between those initially left to stand for 1 hour and those left for 24 hours is small, with the compressive strengths for most mixes being within $6 \mathrm{MPa}$ of each other. The highest alkali dosage $(\mathrm{M}+15 \%)$ gave mixed results, with higher strength for $1 \mathrm{~h}$ stand time for high dosages of silicate solution ( $\mathrm{AM}=1.25$ and 1.5$)$ and the opposite for low dosages $(\mathrm{AM}=2$ and $\infty)$. This might be explained by the fact that reactive silicates trigger the nucleation of gel and therefore, when a significant amount is present (lower AM), the gel formation can start immediately and it is enhanced by the high temperature. On the contrary, when the addition of silicates is low (higher AM), the system needs first to achieve the dissolution of $\mathrm{Si}$ and $\mathrm{Al}$ from the precursor material by the alkali solution at room temperature, whereas the thermal treatment starts the solidification of the gel without allowing enough time for the liquid to complete the dissolution process. Although the difference between no stand time and some stand time can make a difference on strengths by increasing the time for early dissolution and gelation, there appears to be no benefit in leaving mixes for longer than 1 hour between mixing and oven curing. This may be of importance when considering transferring the technology to industry. 


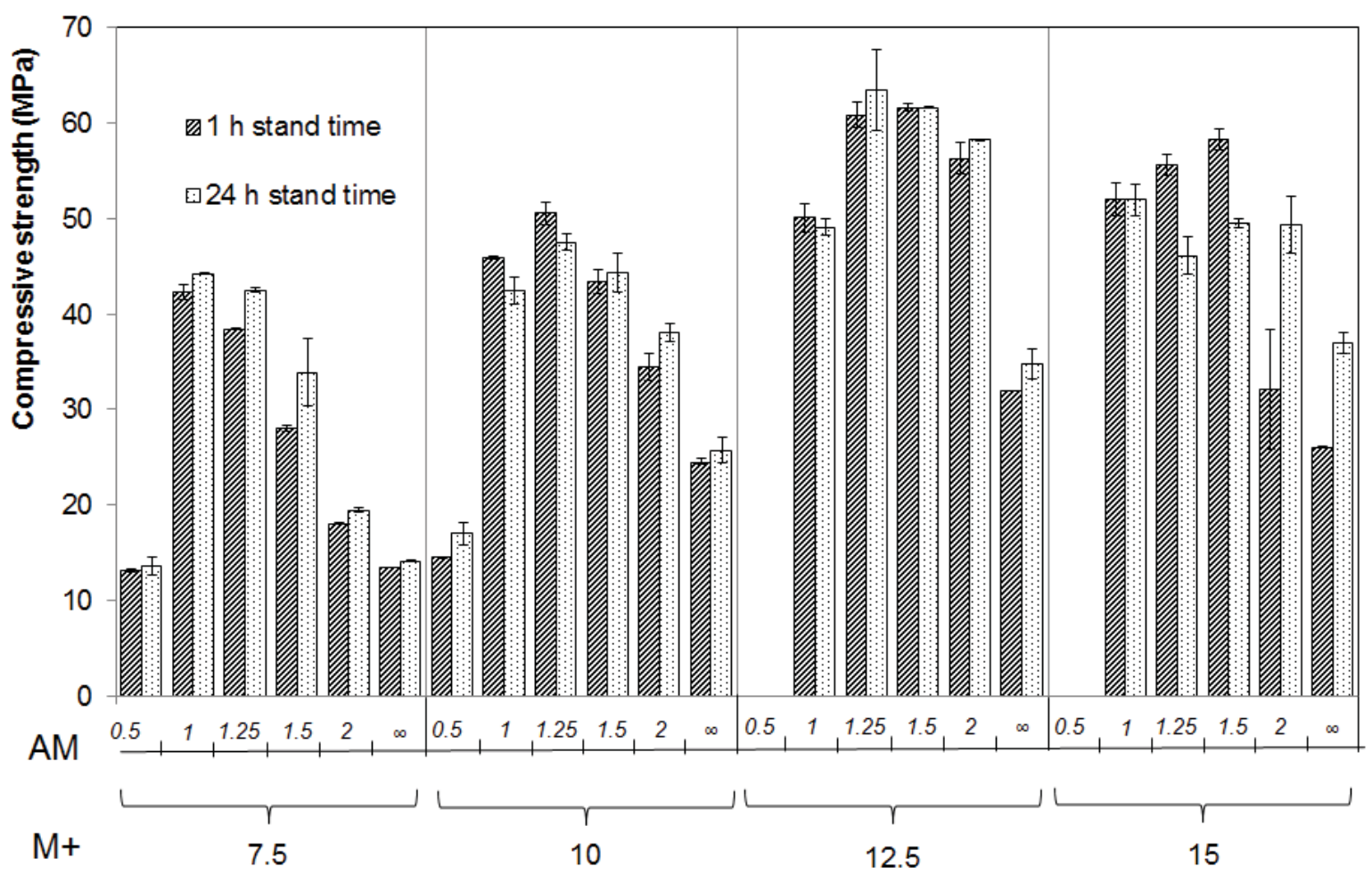

Figure 3. Compressive strengths at 28 days for $1 \mathrm{~h}$ and $24 \mathrm{~h}$ of stand time of $100 \%$ FA mortars $\left(70^{\circ} \mathrm{C}\right.$ curing temperature) for a range of alkali modulus (AM) and alkali dosage $(\mathrm{M}+)$. Error bars represent the range of obtained values.

\subsubsection{Effect of curing temperature}

Figure 4 shows the effect of curing temperature on the 28-day strengths of all mixes. It can be seen that in all cases, with the exception of those with the lowest $\mathrm{AM}(0.5), 70^{\circ} \mathrm{C}$ curing temperatures give significantly increased strengths compared to those cured at $50^{\circ} \mathrm{C}$ for the same time. The same trend was observed irrespective of the "stand time" duration. Mixes with low alkali modulus were extremely viscous and also tended to expand upon thermal curing, forming a muffin like top. Lower curing temperature leads to mitigation of such expansion and this is reflected in the increased strengths.

The observed effect of curing temperature on the mechanical strength is well documented in the literature.

Investigations on reactivity of FA under thermal curing are reported to having been carried out for temperatures in the range $30{ }^{\circ} \mathrm{C}$ to $85^{\circ} \mathrm{C}[25]$. Another study [26] found that increasing the curing temperature from $45{ }^{\circ} \mathrm{C}$ to $65^{\circ} \mathrm{C}$ resulted in a 5 -fold rise of mechanical strength, whereas a 10 -fold rise was observed between $65{ }^{\circ} \mathrm{C}$ and $85^{\circ} \mathrm{C}$. Reaction kinetics resulting from different curing temperature were investigated with 


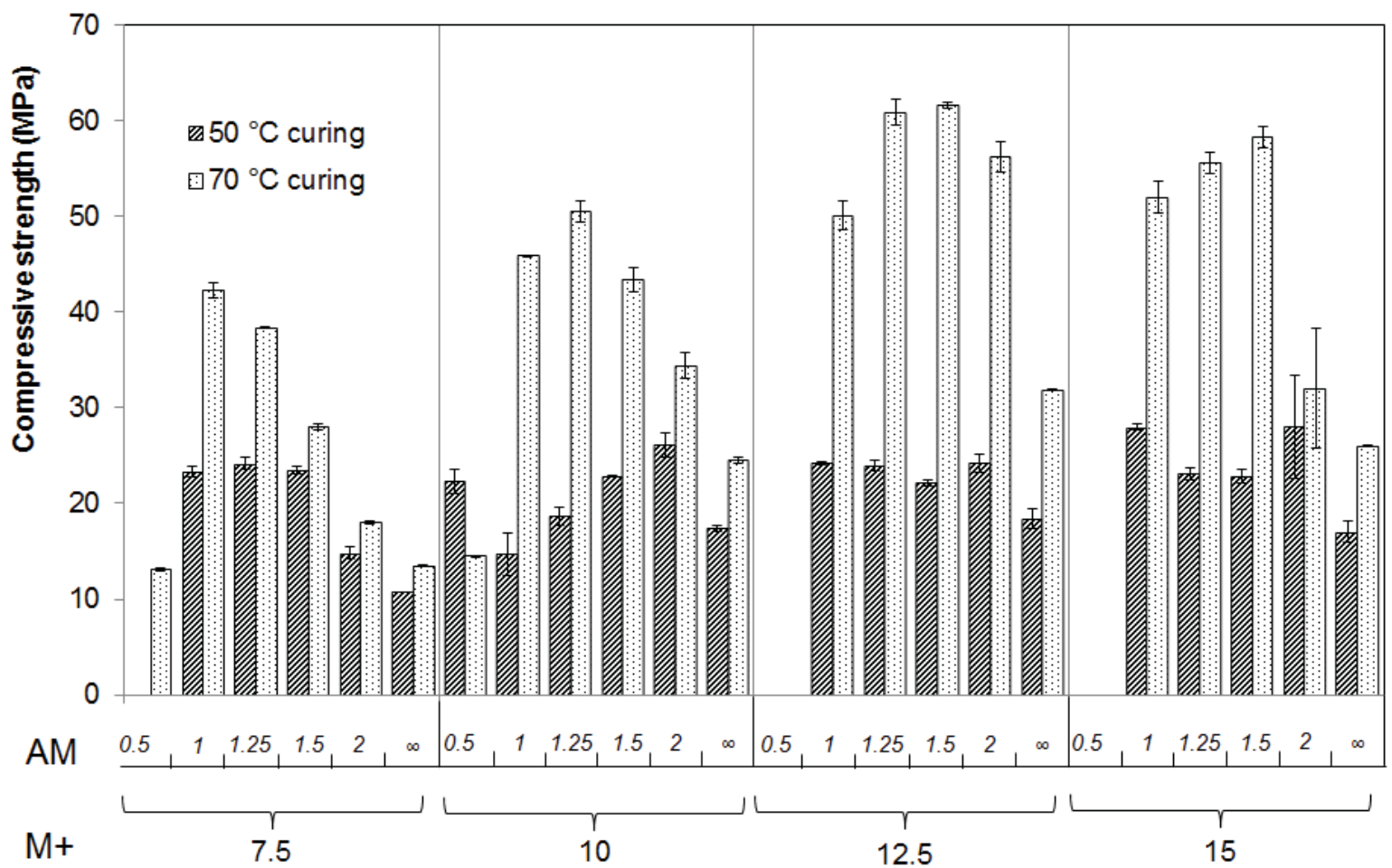

Figure 4. Compressive strengths at 28 days of $100 \% \mathrm{FA}$ mortars for $50^{\circ} \mathrm{C}$ and $70^{\circ} \mathrm{C}$ curing temperatures $(1 \mathrm{~h}$ stand time) for a range of alkali modulus $(A M)$ and alkali dosage $(M+)$. Error bars represent the range of obtained values.

\subsubsection{Effect of Alkali Dosage}

The alkali dosage is a proxy for the alkali concentration, and describes the mass ratio of sodium oxide $\left(\mathrm{Na}_{2} \mathrm{O}\right)$ in the activating solution to FA, where the water to total reactive solids ratio is fixed. An increase in alkali dosage $(\mathrm{M}+)$ resulted in an increase of the strength up to an $\mathrm{M}+$ of $12.5 \%$. Beyond this 'optimum' value, the strengths decreased, which is attributed to saturation of the gel with alkali ions resulting in less free water to be available for speciation of silica and alumina oligomers from the dissolution of FA.

\subsubsection{Effect of Alkali Modulus}

The alkali modulus (AM) is the mass ratio of sodium oxide to silica in the activating solution and it is a proxy for the amount of added silica in the activator solution. An optimum range of values for the alkali modulus was identified, above and below which strengths decrease. With increasing alkali dosage, that 'sweet spot' 

broadens out towards higher alkali modulus. Again, results for $\mathrm{M}+=15 \%$ do not follow these trends. In general, alkali moduli between 1 and 1.25 give the highest strengths across the alkali dosages investigated.

246 The drop-off in strength with increasing modulus is likely to be due to the reduced amount of available silica 247 that can participate in the 'reorganisation-gelation-polymerisation' steps of the geopolymer formation and 248 thus the development of a denser and more complete and long polymer chain. The reduction in strengths at low modulus ( $\mathrm{AM}=0.5$ : all sodium silicate) can be attributed to the reduction of the $\mathrm{pH}$ in the system when only sodium silicate solution is used. The expansion of the cubes upon thermal curing could also have contributed.

Figure 5 shows a 3-D plot identifying the combined effect of alkali dosage and modulus on compressive strength for curing temperature of $70^{\circ} \mathrm{C}$ and "stand time" of 1 hour. These curing conditions were selected because (a) $70^{\circ} \mathrm{C}$ curing temperature gave the highest compressive strengths; (b) as previously discussed, no significant benefit was observed in leaving mixes for stand time longer than 1 hour. at around an alkali dosage of $12.5 \%$ and alkali modulus of 1.25 . 


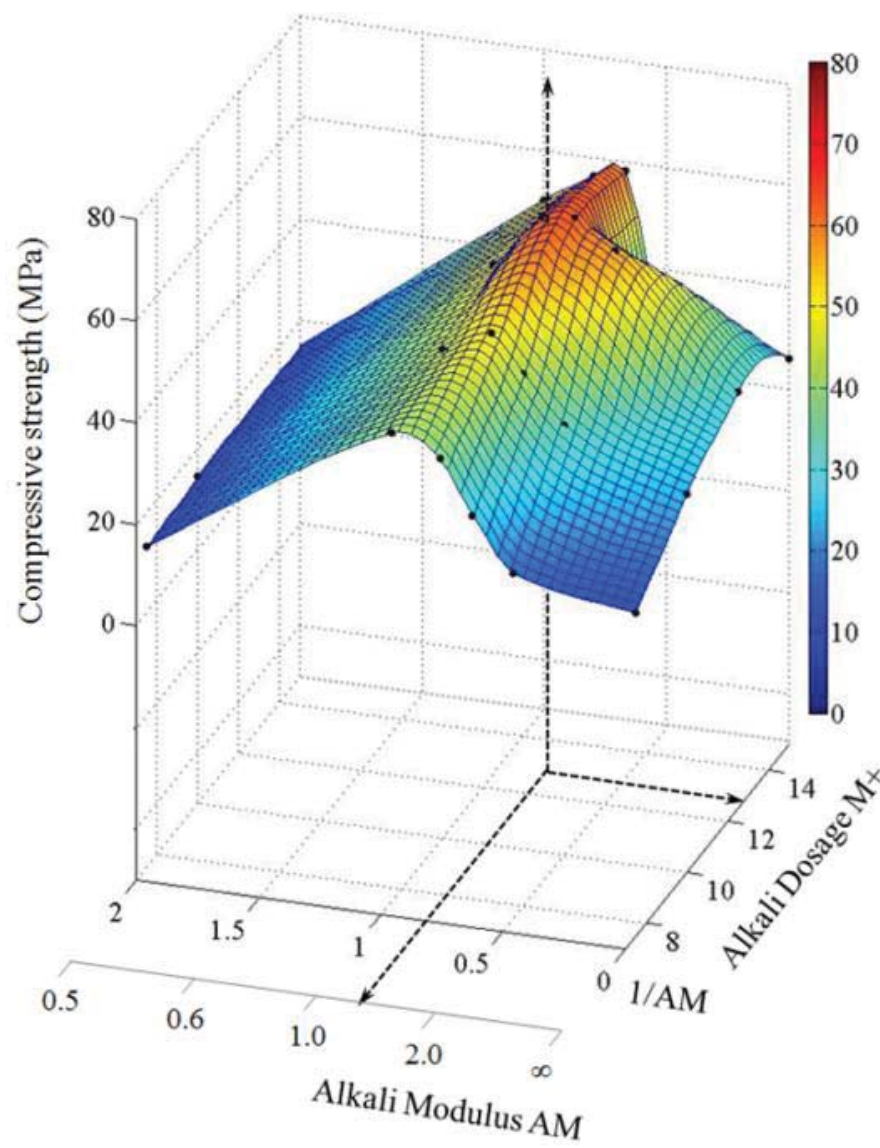

Figure 5. 3-D plot showing the combined effects of alkali dosage and modulus on the 28 -day strength of $100 \%$ FA mortars $\left(1\right.$ hour at $20^{\circ} \mathrm{C}$ followed by $\left.70^{\circ} \mathrm{C}\right)$

\subsection{Influence of physical and chemical properties of raw materials on compressive strength}

A comprehensive characterisation of 13 different fly ashes from coal powered electricity generating stations was carried out in order to investigate the suitability of different FA sources in the UK. Chemical composition, mineralogical composition, grain size distribution and strengths after alkali activation were investigated.

All FA samples conformed to the requirements of the BS EN-450 standard [28] with regards to the $\mathrm{SiO}_{2}+\mathrm{Al}_{2} \mathrm{O}_{3}+\mathrm{Fe}_{2} \mathrm{O}_{3}(\mathrm{SAF}), \mathrm{SO}_{3}, \mathrm{CaO}, \mathrm{MgO}$, and $\mathrm{P}_{2} \mathrm{O}_{5}$ contents, whereas three FA sources $(\mathrm{C}, \mathrm{H}, \mathrm{K})$ had LOI higher than the maximum value (Category C) prescribed in [28]. Physical properties of investigated FAs are shown in Table 2, whereas Table 4 summarises the 28-day compressive strengths from mortars obtained from the different FA sources. It was not possible to cast cubes for testing for four of the investigated FA sources because the mixes were either too dry (FA K and M) or flash setting was experienced (FA I and J). The former 

$\mathrm{MPa}$.

\begin{tabular}{ccccc|c|ccccc}
\hline \multirow{2}{*}{$\begin{array}{c}\text { Ash } \\
\text { source }\end{array}$} & \multicolumn{9}{c}{$\mathbf{7 0}^{\circ}$ curing } & \multicolumn{5}{c}{ 1-day } & 3-day & 7-day & \multicolumn{2}{c|}{ 28-day } & 1-day & 3-day & 7-day & 28-day \\
\hline A & 35.3 & 63.9 & 63.0 & 60.9 & & 3.9 & 25.7 & 24.4 & 24.0 \\
B & 31.4 & 52.1 & 43.5 & 45.7 & 49.2 & 4.2 & 17.8 & 18.2 & 18.6 & 16.9 \\
C & 22.4 & 28.5 & 28.6 & 30.4 & 25.2 & 3.6 & 15.3 & 15.1 & 15.1 & 14.9 \\
D & 41.3 & 63.6 & 60.8 & 53.8 & 54.8 & 7.0 & 20.6 & 24.8 & 26.4 & 27.1 \\
E & 44.1 & 68.2 & 68.1 & 64.1 & 58.7 & 6.9 & 27.0 & 22.2 & 19.3 & 20.2 \\
F & 27.2 & 50.1 & 43.9 & 51.2 & 44.3 & 4.5 & 18.3 & 23.0 & 21.5 & 22.6 \\
G & 20.1 & 36.4 & 32.3 & 27.9 & 39.3 & 3.4 & 18.9 & 18.6 & 17.7 & 17.3 \\
H & 29.1 & 52.7 & 51.1 & 52.0 & 44.0 & 6.0 & 21.1 & 24.5 & 27.1 & 25.4 \\
I & - & - & - & - & - & - & - & - & - & - \\
J & - & - & - & - & - & - & - & - & - & - \\
K & - & - & - & - & - & - & - & - & - \\
L & 50.5 & 62.0 & 63.4 & 61.9 & 58.8 & 10.39 & 23.8 & 40.3 & 38 \\
M & - & - & - & - & - & - & - & - & - \\
\hline
\end{tabular}
for use in concretes if the alkali activator dosage was reduced. This has not however been investigated further.

Optimum activator dosages were used for the geopolymer mortars, i.e. $M+12.5 \%$ and $A M 1.25$. Compressive strength measured at 28 days for samples cured both at $50^{\circ} \mathrm{C}$ and $70^{\circ} \mathrm{C}$ are shown in Figure 6 . The previously identified effect of curing temperature on compressive strength development was confirmed when different FA sources were investigated, with samples cured at $50^{\circ} \mathrm{C}$ showing lower strength than samples cured at $70^{\circ} \mathrm{C}$.

The reaction rate of FA depends on several chemical and physical factors [9, 29]. The content of Si and Al, the amorphous phase content and the loss on ignition (LOI) are important chemical factors. Particle size of the precursor material not only affects the fresh properties (water demand, viscosity, setting time, etc.) but also affects its reactivity. The reduction of the grain size through further milling is known as mechanical activation, and it is commonly adopted for increasing the reactivity of powders [30]. The trend between compressive strength and percentage volume passing $45 \mu \mathrm{m}$ is shown in Figure 7. The value of $45 \mu \mathrm{m}$ was chosen according to the EN-450 [28] as indicative size for determining the fineness of the FA. The strength data were also plotted versus $D_{50}$, i.e. the value of the particle diameter at $50 \%$ in the cumulative distribution, and a similar trend was observed, see Figure 8 . The fineness of the FA appeared therefore to correlate to the compressive strengths, whilst no relationship was observed linking the compressive strength to amorphous content, LOI, or silicon-aluminium-iron oxides (SAF) content for the investigated ashes.

Table 4. Compressive strengths for mortars produced with the 13 FA sources investigated. Values are given in 


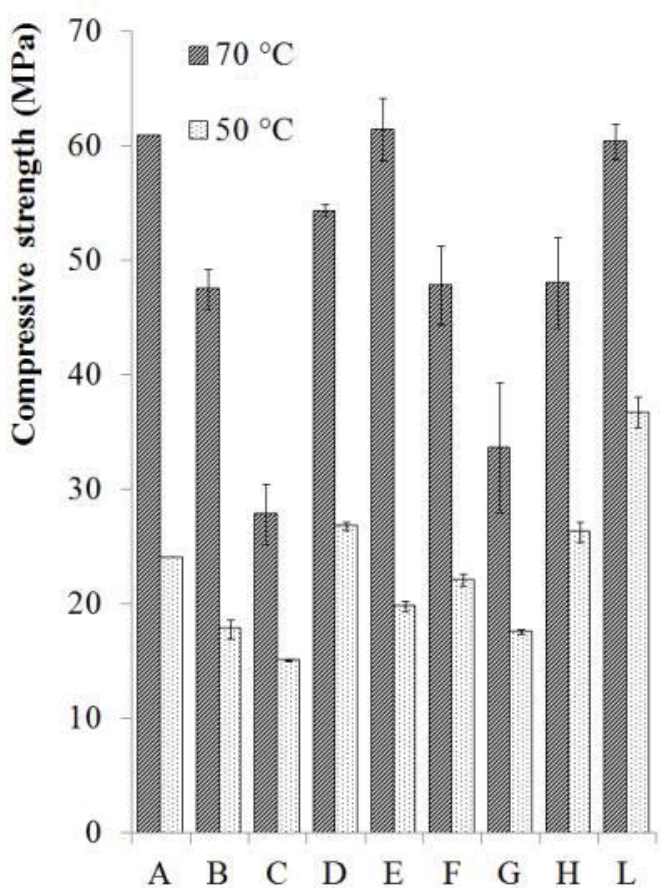

Figure 6. 28-day compressive strength of 9 FA sources at different curing temperatures. Letters A-L equate to same in Table 1 and Figs. 1-2. Error bars represent the range of obtained values.

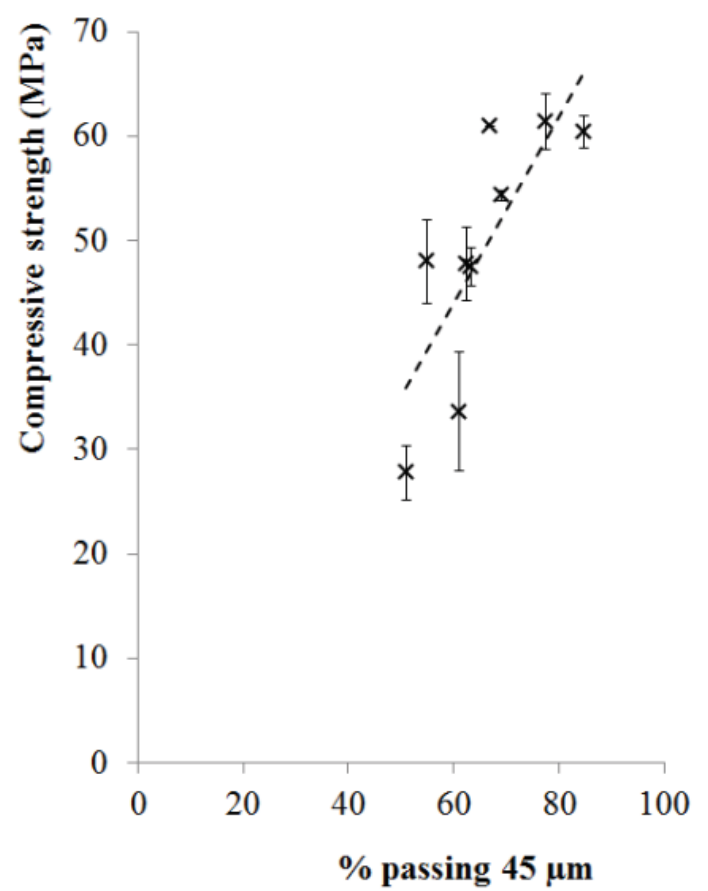

Figure 7. 28-day compressive strength of 9 FA sources cured at $70{ }^{\circ} \mathrm{C}$ vs. $\%$ volume passing $45 \mu \mathrm{m}$ sieve. Error bars represent the range of obtained values. 


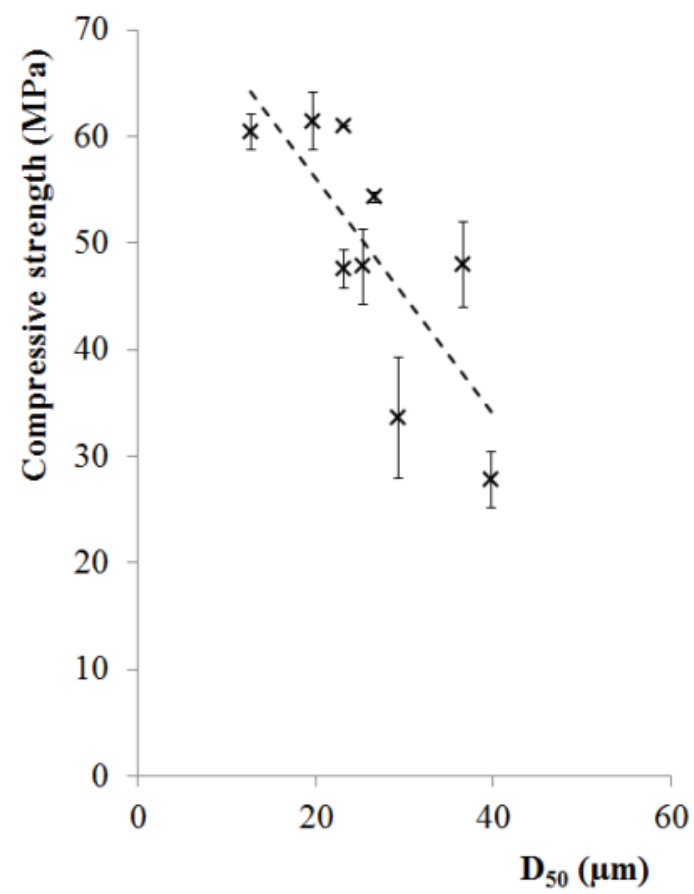

It may therefore be concluded that one of the most important factors to consider for achieving high compressive strengths is the grain size of the FA. It must, however, be emphasised that ten out of thirteen of the tested FA samples are suitable for use in concretes to partially replace Portland cement and thus conform to EN-450. Attempts to examine fuel ash from lagoons did not prove possible. It may be that the chemical composition of lagoon ash has been altered over time and it is thus considerably different from all the sources investigated in this programme of work.

\subsection{Effect of partial replacement of FA with ggbs}

Mortar mixtures containing only FA did not develop any significant strength at room temperature. However, the addition of ggbs at any level gave significant strength enhancements even at room temperature. Figure 9 shows the strength of FA/ggbs based mortars with $\mathrm{M}+7.5 \%$ and $\mathrm{AM} 1.25$. There is an almost linear relationship between the amount of ggbs in the binder and the strength at 1,7 and 28 days where cubes were cured at room temperature $\left(20^{\circ} \mathrm{C}\right)$. This seems to suggest that FA did not contribute much to the strength. There was a significant increase in the strength from $\sim 20 \mathrm{MPa}$ to $~ 50 \mathrm{MPa}$ with the addition of only $20 \%$ ggbs when cured for 1 day at $70^{\circ} \mathrm{C}$. Higher levels of ggbs cured for 1 day resulted in smaller incremental increases up to $60 \mathrm{MPa}$ at $100 \%$ ggbs. 


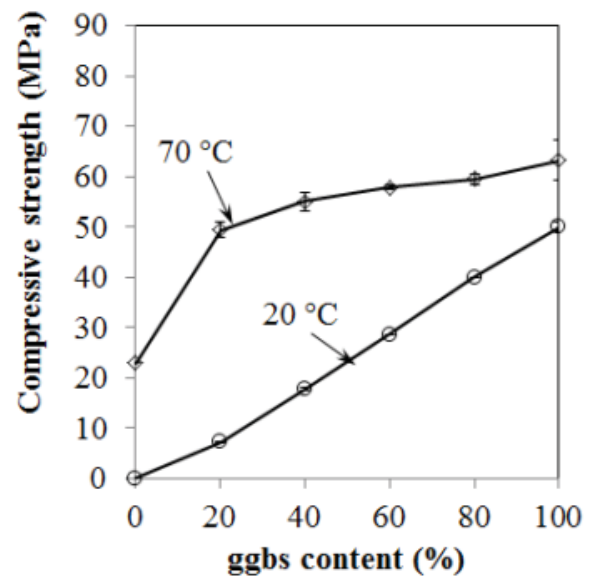

(a)

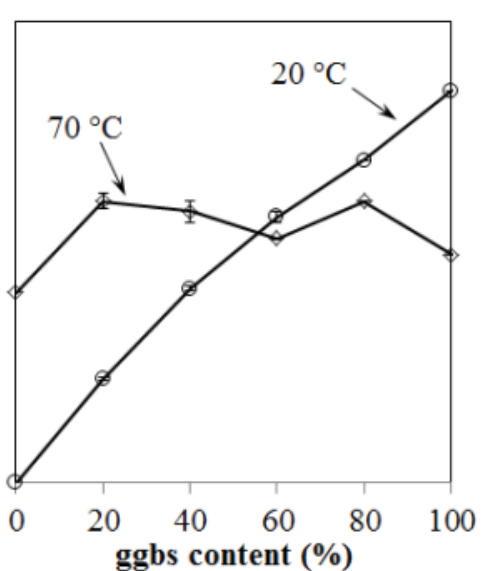

(b)

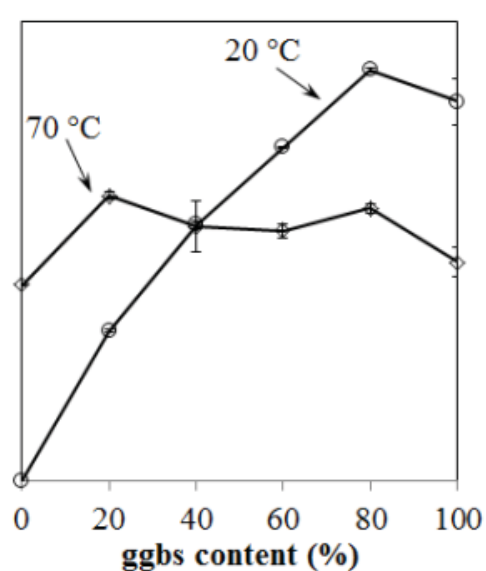

(c)

Figure 9. Effect of ggbs substitution rate on the strength of sodium silicate/sodium hydroxide-activated binders with $M+7.5 \%$ and AM 1.25. (a) 1 day; (b) 7 days; (c) 28 days. Error bars represent the range of obtained values.

Continued curing at $70^{\circ} \mathrm{C}$ for 7 and 28 days resulted in strength reductions for mixes with greater than $20 \%$ ggbs. This is believed to be due to self-desiccation and resulting drying shrinkage, which is an effect that has previously been observed in alkali-activated slags [7]. In accordance with this effect, the highest strength was achieved for specimens cured at room temperature and not for oven-cured samples. Compressive strength of $80 \mathrm{MPa}$ was obtained at 28 days for the mortar containing $80 \%$ slag and cured at room temperature.

Subsequent investigations focussed on the effect of alkali dosage on the strength development of FA/ggbs blends. The AM was kept constant while the $M+$ was varied from $3 \%$ to $10 \%$ for varying levels of FA replacement with ggbs. Figure 10 shows the 3-D plot of the 28-day compressive strength of specimens cured at room temperature. $M+10 \%$ mixes could not be easily cast for ggbs contents higher than $20 \%$ due to quick setting. It can be observed that the increase in ggbs content led to an incremental increase in the compressive strength. 


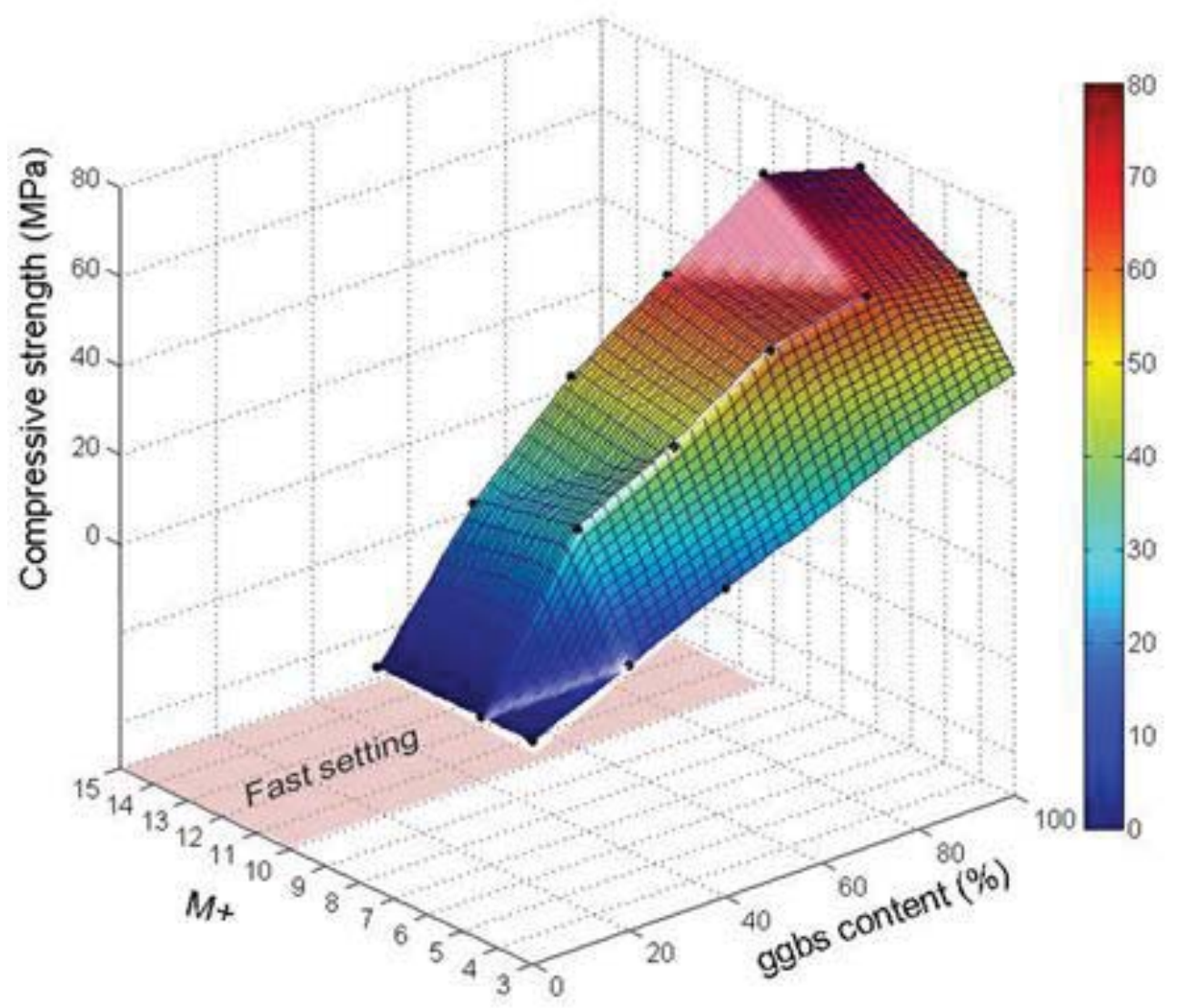

Figure 10. 3-D plot showing the combined effects of FA/ggbs ratio and $\mathrm{M}+$ variation on the 28-day compressive strength of sodium silicate/sodium hydroxide-activated binders cured at room temperature

\subsection{X-Ray Diffraction results for raw materials and reacted pastes}

In order to investigate the nature and composition of the reaction products, raw material and reacted pastes were analysed with X-ray diffraction (XRD) technique. FA A was used for the pastes. The raw materials were activated with the following dosages: $M+7.5 \%, A M=1.25$ and $w / s$ ratio $0.37 .100 \% F A, 100 \%$ ggbs and a $50 / 50$ FA/ggbs paste were produced. After 28 days oven curing at $70{ }^{\circ} \mathrm{C}$, pastes were crushed using distilled water in a McCrone Mill for $5 \mathrm{~min}$ and dried at $50^{\circ} \mathrm{C}$ for 14 hours. An internal standard (zincite, $\mathrm{ZnO}$ ) was included at $10 \%$ in weight for semi-quantitative analysis of the material composition. Diffractograms for unreacted FA showed approximately $75 \%$ of amorphous content, due to the inclusion of the internal standard. After depuration from the $10 \%$ zincite, the main crystalline phases were quartz $\left(\mathrm{SiO}_{2}, 3.9 \%\right.$ in weight), mullite $\left(2 \mathrm{Al}_{2} \mathrm{O}_{3} \cdot \mathrm{SiO}_{2}, 10.6 \%\right.$ in weight $)$, and minor contents of calcite $\left(\mathrm{CaCO}_{3}, 1.4 \%\right.$ in weight $)$ and maghemite $\left(\mathrm{Fe}_{2} \mathrm{O}_{3}\right.$, $0.8 \%$ in weight), whereas the amorphous content was around $83 \%$, in line with the value shown in table 2. Ggbs sample with internal standard showed an amorphous content of about $88 \%$, which resulted in about $98 \%$ 

after depuration from the $10 \%$ crystalline $\mathrm{ZnO}$, with about $1.7 \%$ in weight of crystalline $\mathrm{CaCO}_{3}$ and traces of quartz.

Figure 11 shows the compared diffractograms for 100\% FA (A), 100\% ggbs (B) and 50/50 FA/ggbs (C). 

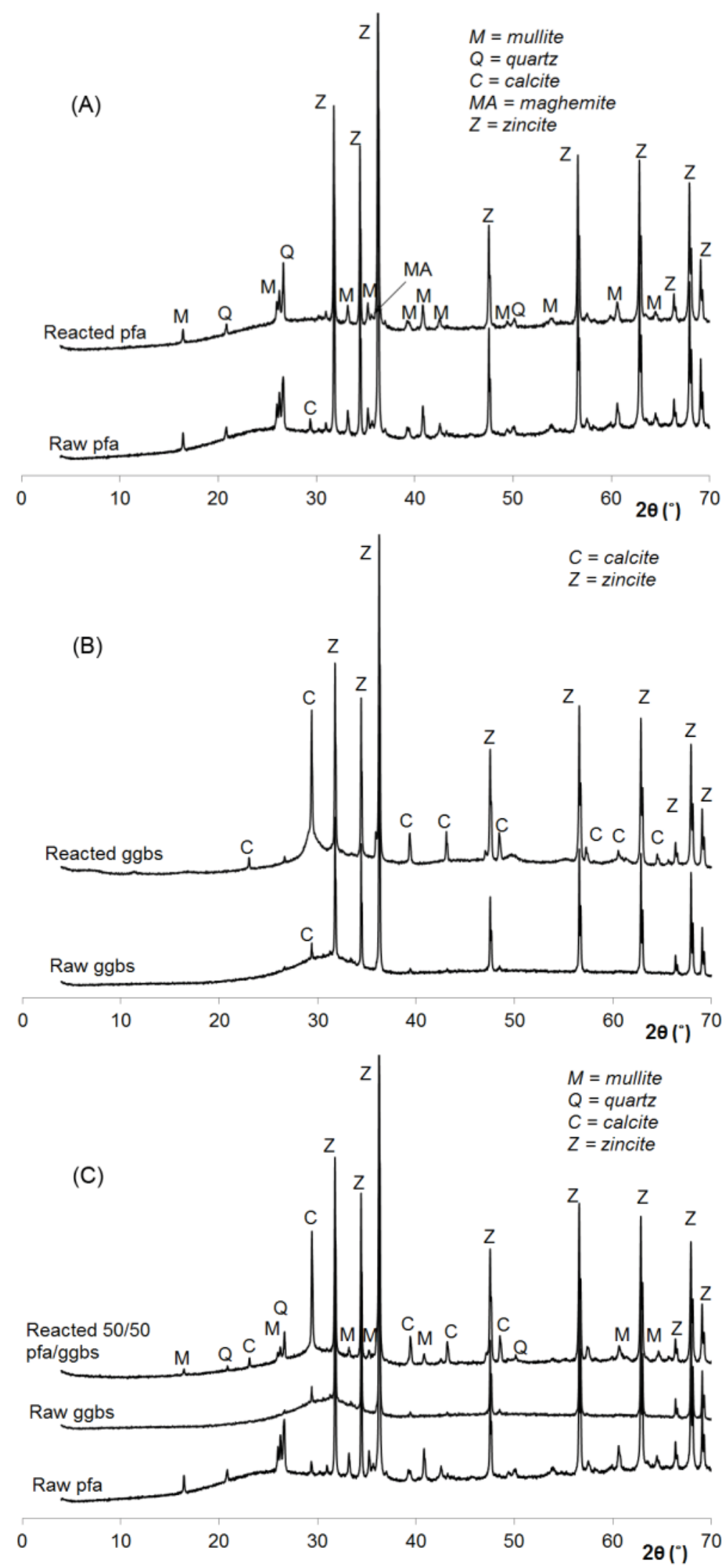

Figure 11. XRD diffractograms of raw materials and reacted pastes. (a) $100 \% \mathrm{FA}$ (b) $100 \%$ ggbs (c) $50 / 50$ $\mathrm{FA} / \mathrm{ggbs}$ 
No new crystalline phase was obtained from the activation of FA. Quartz and mullite, as expected, did not participate to the reaction, as their mass contents remained almost unchanged. On the contrary, the activation of ggbs resulted in a decrease in amorphous content from $98 \%$ to $87 \%$ (corrected values) and in an increase in calcite content from $1.7 \%$ to $9.4 \%$, with peaks for calcite clearly higher in the activated ggbs paste diffractogram. It is likely that the calcite in activated ggbs sample is a combination of high and low crystallinity forms, as apparent by the broad base to the $29.4^{\circ} 2 \theta$ peak.

The 50/50 FA/ggbs paste produced results half way between $100 \%$ ggbs and $100 \%$ FA pastes. Quartz and content did not change, whereas crystalline calcite content increased from $1.5 \mathrm{wt} \%$ of the starting material to $6.0 \mathrm{wt} \%$ of the paste, with the amorphous phase decreasing from $90.7 \%$ to $88 \mathrm{wt} \%$.

\subsection{Microstructure and chemistry of the pastes}

The different mechanical behaviour of FA and FA/ggbs mixes discussed above would be expected to correlate in some way with microstructure or reaction products found in the pastes. To test this, SEM analysis was carried out on the three pastes, i.e. $100 \%$ ggbs, $100 \% \mathrm{FA}$ and $50 / 50 \mathrm{FA} / \mathrm{ggbs}$, cured at $70^{\circ} \mathrm{C}$ for 28 days.

\subsubsection{0\% ggbs paste}

The basic microstructure of $100 \%$ ggbs paste is shown in Figure $12(a)$ and (b). The paste is made up of unreacted particles of ggbs in a smooth and homogenous looking gel. The paste is traversed by interconnecting curved fractures that locally break up the paste into $\sim 10-20 \mu \mathrm{m}$ size conchoidal particles. The fractures have morphologies characteristic of desiccation, particularly evident in Figure 12(b). EDS-based chemical analysis of unreacted ggbs and the surrounding gel from the points indicated in Figure 12(a) are summarised in Table 5 and on the ternary diagram in Figure 13. The vertices of the ternary diagram have been chosen to encompass the main chemical compositions of the gels developed in all three pastes. The $\mathrm{Na}, \mathrm{Ca}$ and Al values in Table 5 have been 'normalised' to Si content in each case in order to alleviate the inherent semiquantitative nature of EDS chemical analysis on rough surfaces. It is worth noting in Figure 13 that the unreacted $100 \%$ ggbs particles and the $100 \%$ ggbs gel form separate clusters that lie on a line that intersects the $\mathrm{Na} / \mathrm{Si}$ corner of the plot (see dashed line in Figure 13). The $100 \%$ ggbs gel thus lies about half way along a potential mixing line between the original ggbs composition and the activator composition, suggesting more or less equal contribution of ggbs and activator in the reaction to produce the gel. 

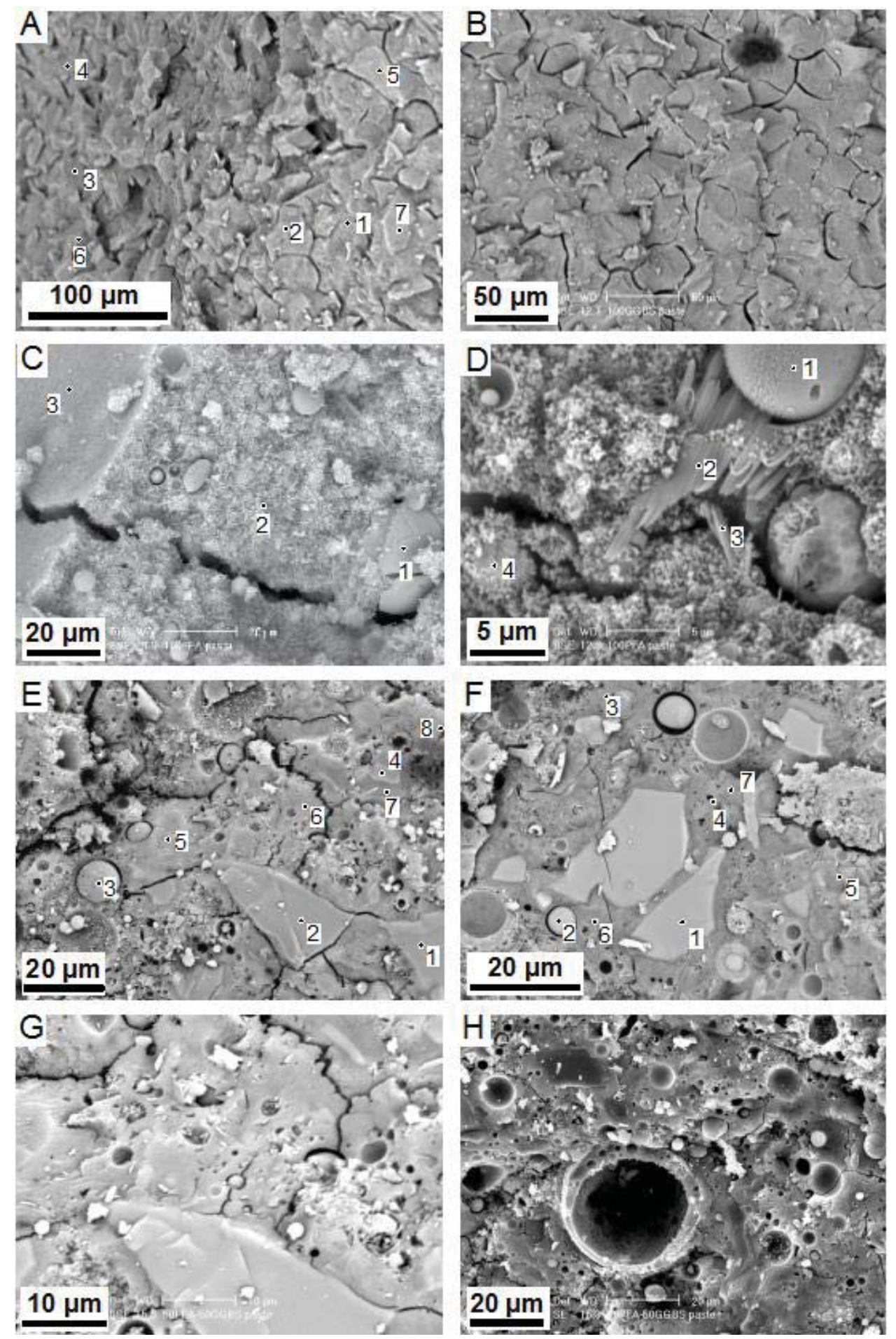

Figure 12. SEM back-scattered electron $(A-G)$ and secondary electron $(H)$ images of geopolymer paste broken surfaces. Numbered spots on A, C, D, E and F are locations of EDS chemical analyses. A \& B: paste made with $100 \%$ ggbs. C\&D: paste made with $100 \%$ FA. E-H: paste made with $50 \%$ ggbs and $50 \%$ FA.

Table 5. EDS analysis of $100 \%$ ggbs paste. Spot numbers refer to Figure $14(a)$. Analyses with Oxford Instruments INCA.

\begin{tabular}{|c|c|c|c|c|c|c|c|c|c|c|c|c|c|c|}
\hline Spot & 0 & $\mathrm{Na}$ & $\mathrm{Mg}$ & Al & $\mathrm{Si}$ & K & $\mathrm{Ca}$ & $\mathrm{Ti}$ & $\mathrm{Mn}$ & $\mathrm{Fe}$ & $\mathrm{Al} / \mathrm{Si}$ & $\mathrm{Ca} / \mathrm{Si}$ & $\mathrm{Na} / \mathrm{Si}$ & Description \\
\hline
\end{tabular}




\begin{tabular}{|c|c|c|c|c|c|c|c|c|c|c|c|c|c|c|}
\hline 1 & 53.42 & 20.99 & 2.00 & 3.22 & 9.96 & 0.15 & 9.95 & 0.13 & 0.17 & & 0.323 & 0.999 & 2.107 & $C-(N)-A-S-H$ gel \\
\hline 2 & 50.95 & 16.29 & 3.13 & 4.03 & 11.07 & 0.31 & 13.69 & 0.27 & 0.23 & & 0.405 & 1.237 & 1.472 & $C-(N)-A-S-H$ gel \\
\hline 3 & 46.93 & 20.21 & 1.07 & 3.00 & 11.38 & 0.42 & 16.63 & 0.23 & & & 0.301 & 1.461 & 1.776 & $C-(N)-A-S-H$ gel \\
\hline 4 & 49.80 & 19.25 & 1.38 & 3.18 & 11.25 & 0.27 & 14.20 & 0.23 & 0.28 & 0.16 & 0.319 & 1.262 & 1.711 & $C-(N)-A-S-H$ gel \\
\hline 5 & 43.54 & 5.30 & 3.60 & 5.80 & 15.09 & 0.41 & 25.23 & 0.28 & 0.60 & & 0.582 & 1.672 & 0.351 & Unreacted ggbs particle \\
\hline 6 & 43.57 & 7.08 & 3.65 & 4.94 & 13.72 & 0.53 & 24.72 & 0.60 & 1.05 & & 0.496 & 1.802 & 0.516 & Unreacted ggbs particle \\
\hline 7 & 36.59 & 3.71 & 3.14 & 5.22 & 15.97 & 0.61 & 33.99 & 0.56 & 0.56 & & 0.524 & 2.128 & 0.232 & Unreacted ggbs particle \\
\hline \multicolumn{15}{|l|}{396} \\
\hline $\begin{array}{l}397 \\
398\end{array}$ & able & . E & nal & of & $\% \mathrm{FA}$ & ct & pot & be & fo & $\mathrm{Fic}$ & 14( & Analy & with & xford \\
\hline
\end{tabular}

\begin{tabular}{cccccccccccccccc}
\hline Spot & $\mathbf{O}$ & $\mathrm{Na}$ & $\mathrm{Mg}$ & $\mathrm{Al}$ & $\mathrm{Si}$ & $\mathrm{K}$ & $\mathrm{Ca}$ & $\mathrm{Ti}$ & $\mathrm{Mn}$ & $\mathrm{Fe}$ & $\mathrm{Al} / \mathrm{Si}$ & $\mathrm{Ca} / \mathrm{Si}$ & $\mathrm{Na} / \mathrm{Si}$ & Description \\
\hline 1 & 47.27 & 2.78 & 0.76 & 15.02 & 26.5 & 3.58 & 0.94 & 0.78 & 2.36 & 1.508 & 0.035 & 0.105 & Unreacted FA particle \\
2 & 54.2 & 8.53 & 0.54 & 11.15 & 19.08 & 1.51 & 2.08 & 0.28 & 2.62 & 1.119 & 0.109 & 0.447 & N-A-S-H gel \\
3 & 49.77 & 10.24 & 0.58 & 8.96 & 22.88 & 2.18 & 2.7 & 0.51 & 2.17 & 0.900 & 0.118 & 0.448 & N-A-S-H gel \\
\hline 399 & & & & & & & & & & & & & & &
\end{tabular}

400 Table 6(b). EDS analysis of 100\% FA paste. Spot numbers refer to Figure 14 (d). Analyses with Oxford 401 Instruments INCA.

\begin{tabular}{|c|c|c|c|c|c|c|c|c|c|c|c|c|c|c|}
\hline Spot & 0 & $\mathrm{Na}$ & $\mathrm{Mg}$ & Al & $\mathrm{Si}$ & K & $\mathrm{Ca}$ & $\mathrm{Ti}$ & $\mathrm{Mn}$ & $\mathrm{Fe}$ & $\mathrm{Al} / \mathrm{Si}$ & $\mathrm{Ca} / \mathrm{Si}$ & $\mathrm{Na} / \mathrm{Si}$ & Description \\
\hline 1 & 53.09 & 1.21 & 0.89 & 14.18 & 23.50 & 2.89 & 1.34 & 0.44 & \multirow{4}{*}{0.23} & 2.37 & 1.424 & 0.057 & 0.051 & Unreacted FA particle \\
\hline 2 & 47.03 & 14.67 & 0.53 & 9.57 & 20.68 & 1.94 & 1.72 & 0.42 & & 3.20 & 0.961 & 0.083 & 0.709 & N-A-S crystal \\
\hline 3 & 48.34 & 18.89 & 0.49 & 7.77 & 17.44 & 1.93 & 1.63 & 0.53 & & 3.03 & 0.780 & 0.093 & 1.083 & N-A-S crystal \\
\hline 4 & 51.39 & 7.02 & 0.76 & 11.05 & 21.23 & 1.93 & 2.11 & 1.18 & & 3.29 & 1.109 & 0.099 & 0.331 & N-A-S-H gel \\
\hline \multicolumn{15}{|l|}{402} \\
\hline $\begin{array}{l}403 \\
404\end{array}$ & \multicolumn{14}{|c|}{$\begin{array}{l}\text { Table 7(a). EDS analysis of 50/50 FA/ggbs paste ( } 1^{\text {st }} \text { sample). Spot numbers refer to Figure } 14(e) \text {. Analyses with } \\
\text { Oxford Instruments INCA. }\end{array}$} \\
\hline Spot & 0 & $\mathrm{Na}$ & $\mathrm{Mg}$ & Al & $\mathrm{Si}$ & $\mathbf{K}$ & $\mathrm{Ca}$ & $\mathrm{Ti}$ & Mn & $\mathrm{Fe}$ & Si/Al & $\mathrm{Ca} / \mathrm{Si}$ & $\mathrm{Na} / \mathrm{Si}$ & Description \\
\hline 1 & 38.00 & 0.27 & 4.86 & 6.98 & 18.58 & 0.51 & 29.44 & 0.63 & 0.46 & 0.26 & 0.701 & 1.584 & 0.015 & Unreacted ggbs particle \\
\hline 2 & 29.37 & 0.37 & 4.41 & 7.49 & 19.39 & 0.51 & 37.24 & 0.61 & 0.39 & 0.23 & 0.752 & 1.921 & 0.019 & Unreacted ggbs particle \\
\hline 3 & 45.51 & 1.25 & 1.17 & 18.27 & 24.38 & 2.19 & 1.22 & 0.64 & & 5.39 & 1.834 & 0.050 & 0.051 & Unreacted FA particle \\
\hline 4 & 40.95 & 0.47 & 4.53 & 6.95 & 17.02 & 0.47 & 28.54 & 0.40 & 0.32 & 0.37 & 0.698 & 1.677 & 0.027 & Unreacted ggbs particle \\
\hline 5 & 49.12 & 8.41 & 1.21 & 7.04 & 20.92 & 1.28 & 10.44 & 0.39 & & 1.06 & 0.707 & 0.499 & 0.402 & C-(N)-A-S-H gel \\
\hline 6 & 48.95 & 5.10 & 2.83 & 6.42 & 17.77 & 1.03 & 16.37 & 0.31 & 0.38 & 0.87 & 0.645 & 0.921 & 0.287 & $C-(N)-A-S-H$ gel \\
\hline 7 & 40.81 & 5.41 & 2.20 & 6.96 & 21.86 & 1.55 & 19.17 & 0.44 & 0.49 & 1.12 & 0.699 & 0.877 & 0.247 & C-(N)-A-S-H gel \\
\hline 8 & 39.53 & 6.31 & 1.93 & 8.45 & 23.71 & 1.55 & 15.8 & 0.39 & 0.5 & 1.84 & 0.848 & 0.666 & 0.266 & $C-(N)-A-S-H$ gel \\
\hline
\end{tabular}
405

406

407

408 Table $7(b)$. EDS analysis of $50 \% / 50 \%$ FA/ggbs paste $\left(2^{\text {nd }}\right.$ sample). Spot numbers refer to Figure $14(f)$. Analyses 409 with Bruker Quantax 70.

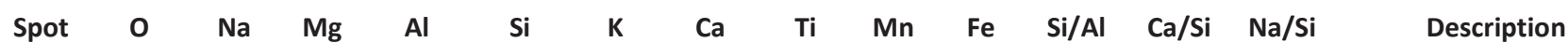




\begin{tabular}{ccccccccccccccc}
\hline 1 & 44.01 & 1.20 & 4.42 & 6.33 & 17.39 & 0.52 & 24.98 & 0.46 & 0.55 & 0.13 & 0.636 & 1.436 & 0.069 & Unreacted ggbs particle \\
2 & 44.37 & 3.06 & 1.19 & 16.12 & 26.12 & 3.51 & 2.16 & 0.37 & & 3.10 & 1.618 & 0.083 & 0.117 & Unreacted FA particle \\
3 & 51.08 & 7.82 & 1.08 & 6.88 & 18.22 & 1.85 & 12.79 & 0.27 & & & 0.691 & 0.702 & 0.429 & C-(N)-A-S-H gel \\
4 & 49.55 & 7.53 & 0.86 & 7.16 & 18.21 & 2.14 & 12.67 & 0.57 & 0.41 & 0.89 & 0.719 & 0.696 & 0.414 & C-(N)-A-S-H gel \\
5 & 46.36 & 8.01 & 1.54 & 7.12 & 20.92 & 0.96 & 13.64 & 0.24 & & 1.20 & 0.715 & 0.652 & 0.383 & C-(N)-A-S-H gel \\
6 & 49.03 & 8.32 & 1.78 & 7.18 & 20.29 & 2.05 & 10.17 & 0.29 & 0.25 & 0.65 & 0.721 & 0.501 & 0.410 & C-(N)-A-S-H gel \\
7 & 51.84 & 7.97 & 1.54 & 5.95 & 17.14 & 1.54 & 12.17 & & 0.89 & 0.97 & 0.597 & 0.710 & 0.465 & C-(N)-A-S-H gel \\
\hline 410 & & & & & & & & & & & & & &
\end{tabular}

\section{$411 \quad 3.5 .2 \quad 100 \%$ FA paste}

412 The basic microstructure of $100 \%$ FA paste is shown in Figure $12(\mathrm{c})$ and (d). The paste is made up of unreacted particles of FA in a rough and sugary looking granular gel. There are commonly gaps between the gel and the unreacted FA suggesting weak bonding of gel to unreacted particles. Some long fractures are present, but these have a morphology suggesting they formed during breakage of the sample rather than by desiccation. EDS-based chemical analysis of unreacted FA and the surrounding gel from the points indicated in Figure 12(c) and (d) are summarised in Table 6(a) and (b) as well as on the ternary diagram in Figure 13. It is clear that the FA cenospheres are relatively enriched in Al and depleted in $\mathrm{Ca}$ and Na relative to Si content. On the other hand, the rough sugary gel is relatively enriched in $\mathrm{Na}$ and slightly enriched in Ca relative to the unreacted FA. In this case, the unreacted FA and the gel do not lie directly on a potential mixing line between the unreacted available $\mathrm{Ca}$ in the FA into the gel.

\subsubsection{0\% FA and 50\% ggbs paste}

The basic microstructure of 50\% FA and 50\% ggbs paste is shown in Figure $12(\mathrm{e})$ and (f). The paste is made up of unreacted particles of FA and ggbs in a smooth homogeneous looking gel. The microstructure for 50/50 FA/ggbs shows unreacted or partially reacted FA cenospheres and ggbs grains surrounded by an amorphous matrix which was smooth and homogeneous in some places whilst rough and more heterogeneous in others. There are relatively few fractures, which do not look like desiccation fractures. The contact between gel and unreacted ggbs is typically sharp, whereas there is often a gap between the gel and unreacted FA cenospheres; the large cenosphere in the centre of Figure 12(h) is an exception. EDS-based chemical analysis of unreacted FA/ggbs and the surrounding gel from the points indicated in Figure 12(e) and (f) are summarised in Table 7(a) and (b) as well as on the ternary diagram in Figure 13. The unreacted ggbs and FA have compositions similar to 
those in the 100\%ggbs and 100\%FA pastes, respectively (Figure 13). The gel has a composition that lies within a triangle formed by the unreacted FA and ggbs and the alkali-activator composition indicating all three reactants were involved in the reaction to produce the gel. The position of the gel composition relative to the reactants indicates ggbs was the main contributor to the gel and the alkali activator the least.

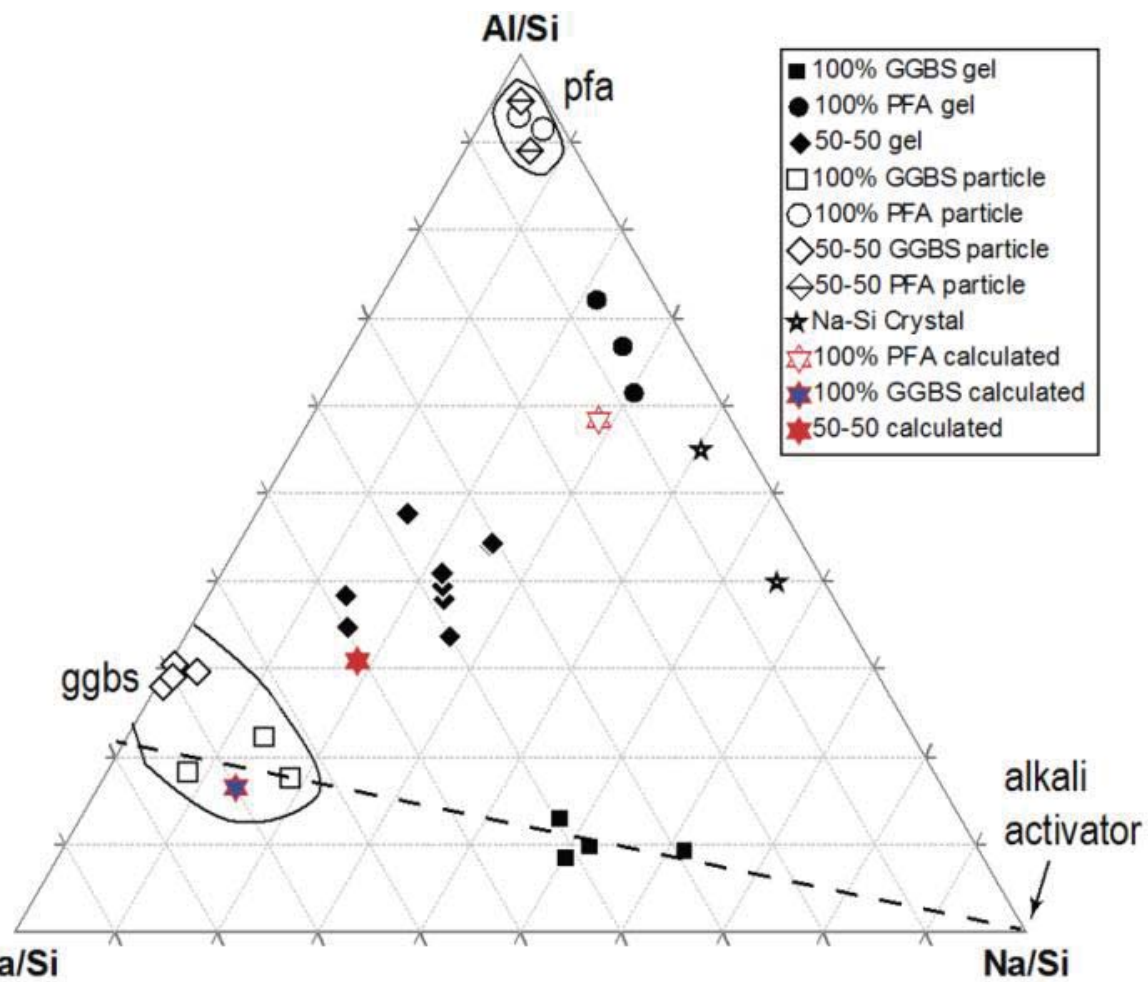

Figure 13. Triangular plot of $\mathrm{Ca}, \mathrm{Al}, \mathrm{Na}$ compositions normalised to Si content for FA and GGBS particles, various gels, and some Na-Si crystals formed in one sample. Calculated compositions for the pastes are plotted as six pointed stars. Added $\mathrm{NaOH}$ and sodium silicate solution would plot on the $\mathrm{Na} / \mathrm{Si}$ corner. See text for further explanation and discussion.

The three microstructures are quite different. The 100\% FA gel looks granular and potentially porous with a commonly poor adhesion to unreacted FA particles. In contrast the $100 \%$ ggbs gel is homogeneous and looks denser, but is cut by interconnecting desiccation cracks. Both microstructures look inherently weak. The 50\%FA-50\%ggbs gel microstructure is homogeneous and dense looking and lacks the desiccation cracks found in the $100 \%$ ggbs gel. The addition of aluminium from the FA has resulted in a non-granular gel that does not shrink, and is perhaps stronger.

Overall, the main product from a FA-based system is a sodium-alumina-silicate-hydrate geopolymeric gel (N-A$\mathrm{S}-\mathrm{H}$ ) with very low $\mathrm{Ca} / \mathrm{Si}$ ratio, though perhaps a little higher than would be expected from the compositions of 
FA and the alkali activator. The gel composition is similar to the calculated bulk composition of the gel ingredients (Figure 13).

In contrast, the high calcium $100 \%$ ggbs system produces a calcium-alumina-silicate-hydrate gel (C-A-S-H) with low $\mathrm{Al} / \mathrm{Si}$ ratio of $0.3-0.4$ and a $\mathrm{Ca} / \mathrm{Si}$ of 1 to 1.5, as has been reported by several researchers [31-33] for alkali activated slag systems. The reaction products are similar to the C-S-H gel in Portland cement systems, where higher $\mathrm{Ca} / \mathrm{Si}$ ratios are obtained in the range 1.2 to 2.3 [34], and are presumably various forms of calcium silicate hydrates and calcium aluminium hydrates. The gel composition is much more Na-rich than the calculated bulk composition of the gel ingredients and even the unreacted ggbs particles contain significant $\mathrm{Na}$ (Figure 13). Re-examination of the same surface about 9 months later revealed a coating of sodium carbonate crystals in rosette forms (Figure 14) indicating an excess of $\mathrm{Na}$ in the gel reaction. These rosettes were not visible shortly after the $100 \%$ ggbs paste was made (see Figure $12(a)$ and (b)). This raises the possibility that the higher than expected Na measurements from the surfaces in Figure 12 (a) and (b) reflect initial submicroscopic formation of sodium carbonate crystals at the sample surface as efflorescence due to evaporation of excess sodium-bearing solute, which as it progressed led to formation of the larger rosette crystals. Thus, it is suggested that the $100 \%$ ggbs gel at the broken sample surface has progressively incorporated Na from the alkali activator.

The $50 \%$ FA $50 \%$ ggbs system produces a C-A-S-H gel with $\mathrm{Na} / \mathrm{Si}$ in the range $0.25-0.5, \mathrm{Ca} / \mathrm{Si}$ at $0.5-0.9$ and $\mathrm{Si} / \mathrm{Al}$ at 0.6-0.85, compositions similar to the calculated bulk composition of the gel ingredients (Figure 13). The gel microstructure looks dense and is uncracked. It has been reported in [35] that alkalis ( $\mathrm{Na}$ in this case) can be incorporated into a C-A-S-H gel structure in order to balance the charge of tetrahedral Al, therefore it could also be written C-(N)-A-S-H. As suggested in the literature [36], the calcium silicate hydrate gel fills the pores and voids left by the water escaping the "pure" geopolymeric gel (N-A-S-H), resulting in a more compact and dense structure that is responsible for the increase in mechanical strength compared to the $100 \%$ pfa paste. The coexistence of N-A-S-H and C-A-S-H gels has been reported in the literature [33, 36-37]. 

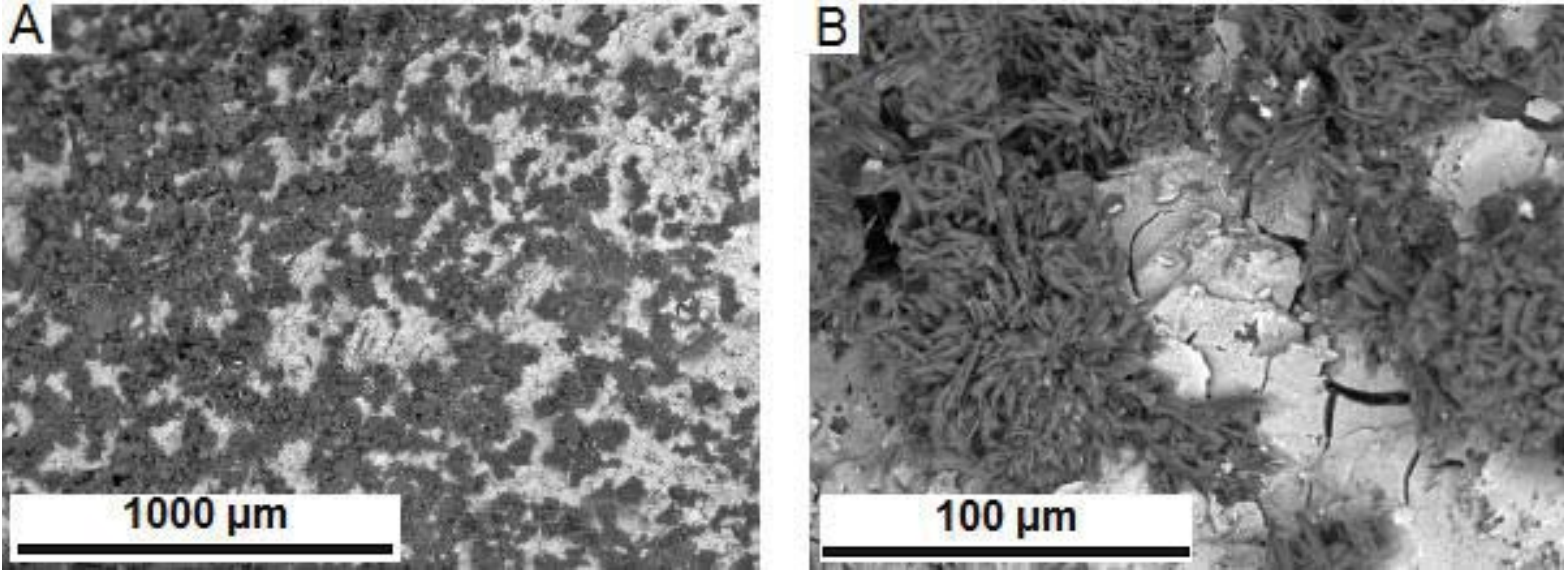

Figure 14. Back-scattered electron images of $100 \%$ ggbs paste surface $\sim 9$ months after images in Figure 12 . A shows distribution of sodium carbonate crystals (dark areas) grown on the paste surface (light area). B shows a detail of the rosette structure formed by the sodium carbonate crystals and the characteristic desiccation cracks in the gel.

\section{Conclusions}

Geopolymer and alkali activated binders can offer a possible alternative to Portland cement concrete.

Notwithstanding all the research work that has been carried out all over the world, an easy way of selection of raw material and their proportioning to obtain desired properties has remained a trial and error procedure.

The following factors affecting the mechanical properties were therefore investigated in order to provide guidance for the selection of raw materials and their proportioning to produce geopolymer concretes of the required properties: (a) the effect of curing procedure and activator dosages on the strength of FA-based mortar; (b) the influence of physical and chemical properties of different FA sources; (c) the effect of partial FA replacement with ggbs.

The conclusions from this work are:

1. Curing temperature has a very significant effect on strength of FA based geopolymers: specimens cured at $70^{\circ} \mathrm{C}$ were considerably stronger than specimens cured at $50^{\circ} \mathrm{C}$. Stand time was found to be less important and as such an 1 hour stand time before oven curing was considered sufficient.

2. The dosage of activators is very important for not only achieving the required early age properties but also for the effect on compressive strength. A 'sweet spot' of the optimum alkali modulus and dosage combinations, i.e. alkali dosage of $12.5 \%$ and alkali modulus of 1.25 , gave compressive strength of $\sim 70$ MPa. 
3. Physical and chemical properties of potential FA sources should be investigated before selecting the most suitable one. Average grain size was found to be one of the important factors affecting the potential compressive strength. Coarse FA coupled with low amorphous content and high LOI needs to be avoided.

4. Partial FA replacement with ggbs leads to increases in the compressive strength. Strengths of $80 \mathrm{MPa}$ with only $M+7.5 \%$ and $A M 1.25$ were obtained. The other benefit from such blends is that curing at room temperature only is sufficient and no elevated curing temperatures are needed.

5. SEM investigation on pastes of $100 \% \mathrm{FA}, 100 \%$ ggbs and $50 / 50 \mathrm{FA} /$ ggbs assisted in determining the microstructure, reaction products and their chemical composition. The $100 \%$ FA and $100 \%$ ggbs mixes produce distinctly different microstructures, i.e. dominated by coarse granularity and desiccation cracking respectively. The 50/50 FA/ggbs mix develops a homogeneous, dense gel with little microcracking and good bonding to unreacted ggbs and FA particles. The 50/50 FA/ggbs microstructure looks like it should be stronger and it has been proved to be so when $70^{\circ} \mathrm{C}$ oven curing conditions are applied.

6. A calcium alumina silicate hydrate gel with inclusions of $\mathrm{Na}^{+}$cations in the structure was found in the samples containing ggbs. This was denser than the sodium alumina silicate hydrate gel (N-A-S-H) found for $100 \%$ FA samples and this could explain the improved compressive strengths.

\section{Acknowledgements}

This research was carried out at the University of Liverpool in the framework of the Carbon Trust Applied Research Grant 0911-0252 “Ultra High Performance Fibre Reinforced Cementless Precast Concrete Products". The work was then continued at Queen's University of Belfast with the financial support of the SUSCON project, which has received funding from the European Union Seventh Framework Programme (FP7/20072013) under Grant Agreement No. 285463 (Call FP7-2011-NMP ENV-ENERGY-ICT-EeB).

\section{References}

[1] Davidovits, J. (2008) Geopolymer chemistry and applications. Institut Geopolymere. 
[2] Davidovits, J. (1989). Geopolymers and geopolymeric materials. Journal of thermal analysis, 35(2), 429-441.

[3] Davidovits, J. (1991). Geopolymers. Journal of thermal analysis, 37(8), 1633-1656.

[4] Davidovits, J. (1993). Geopolymer cements to minimise carbon-dioxide greenhouse-warming. Ceram. Trans., 37, 165-182.

[5] Barbosa, V. F., MacKenzie, K. J., \& Thaumaturgo, C. (2000). Synthesis and characterisation of materials based on inorganic polymers of alumina and silica: sodium polysialate polymers. International Journal of Inorganic Materials, 2(4), 309-317.

[6] Kriven, W. M., Bell, J. L., \& Gordon, M. (2003). Microstructure and Microchemistry of Fully-Reacted Geopolymers and Geopolymer Matrix Composites. Advances in Ceramic Matrix Composites IX, Volume 153, 227-250.

[7] Shi, C., Roy, D., \& Krivenko, P. (2006). Alkali-activated cements and concretes. CRC press.

[8] Van Jaarsveld, J. G. S., \& Van Deventer, J. S. J. (1999). Effect of the alkali metal activator on the properties of fly ash-based geopolymers. Industrial \& Engineering Chemistry Research, 38(10), 3932 3941.

[9] Provis, J. L, van Deventer, J. S. (2014). Alkali Activated Materials. J. L. Provis (Ed.). Springer.

[10] Jimenez, A. M. F., Lachowski, E. E., Palomo, A., \& Macphee, D. E. (2004). Microstructural characterisation of alkali-activated PFA matrices for waste immobilisation. Cement and Concrete Composites, 26(8), 1001-1006.

[11] Kong, D. L., \& Sanjayan, J. G. (2010). Effect of elevated temperatures on geopolymer paste, mortar and concrete. Cement and Concrete Research, 40(2), 334-339.

[12] Wallah, S. E., \& Rangan, B. V. (2006). Low-calcium fly ash-based geopolymer concrete: long-term properties. Res. Report-GC2, Curtin University, Australia. pp, 76-80.

[13] Duxson, P., Fernández-Jiménez, A., Provis, J. L., Lukey, G. C., Palomo, A., \& Van Deventer, J. S. J. (2007). Geopolymer technology: the current state of the art. Journal of Materials Science, 42(9), 29172933.

[14] Andini, S., Cioffi, R., Colangelo, F., Grieco, T., Montagnaro, F., \& Santoro, L. (2008). Coal fly ash as raw material for the manufacture of geopolymer-based products. Waste management, 28(2), 416-423. 
[15] Duxson, P., Provis, J. L., Lukey, G. C., \& Van Deventer, J. S. (2007). The role of inorganic polymer technology in the development of 'green concrete'. Cement and Concrete Research, 37(12), 15901597.

[16] Soutsos, M.N., Vinai, R., \& Rafeet, A. (2015). Effect of alkali dosage and modulus on strength development and microstructure of alkali-activated binders. $14^{\text {th }}$ International Congress on the Chemistry of Cement (ICCC 2015), 13-16 October 2015, Beijing, China

[17] Department of Energy \& Climate Change, Electricity: chapter 5, Digest of United Kingdom energy statistics (DUKES). https://www.gov.uk/government/statistics/electricity-chapter-5-digest-of-unitedkingdom-energy-statistics-dukes. Accessed on 17 June 2015.

[18] Heath, A., Paine, K., Goodhew, S., Ramage, M., \& Lawrence, M. (2013). The potential for using geopolymer concrete in the UK. Proceedings of the Institution of Civil Engineers: Construction Materials, 166(4), 195-203.

[19] Puertas, F., \& Fernández-Jiménez, A. (2003). Mineralogical and microstructural characterisation of alkali-activated fly ash/slag pastes. Cement and Concrete composites, 25(3), 287-292.

[20] Puertas, F., Martínez-Ramírez, S., Alonso, S., \& Vazquez, T. (2000). Alkali-activated fly ash/slag cements: strength behaviour and hydration products. Cement and Concrete Research, 30(10), 16251632.

[21] Puligilla, S., \& Mondal, P. (2013). Role of slag in microstructural development and hardening of fly ashslag geopolymer. Cement and Concrete Research, 43, 70-80.

[22] Ismail, I., Bernal, S. A., Provis, J. L., San Nicolas, R., Hamdan, S., \& van Deventer, J. S. (2014). Modification of phase evolution in alkali-activated blast furnace slag by the incorporation of fly ash. Cement and Concrete Composites, 45, 125-135.

[23] Kumar, S., Kumar, R., \& Mehrotra, S. P. (2010). Influence of granulated blast furnace slag on the reaction, structure and properties of fly ash based geopolymer. Journal of Materials Science, 45(3), 607-615.

[24] British Standards Institution, Testing fresh concrete - Part 5: Flow table test, BS EN 12350-5:2000.

[25] Kovalchuk, G., Fernández-Jiménez, A., \& Palomo, A. (2007). Alkali-activated fly ash: effect of thermal curing conditions on mechanical and microstructural development-Part II. Fuel, 86(3), 315-322. 
[26] Palomo, A., Alonso, S., Fernandez-Jiménez, A., Sobrados, I., \& Sanz, J. (2004). Alkaline activation of fly ashes: NMR study of the reaction products. Journal of the American Ceramic Society, 87(6), 11411145.

[27] Chithiraputhiran, S., \& Neithalath, N. (2013). Isothermal reaction kinetics and temperature dependence of alkali activation of slag, fly ash and their blends. Construction and Building Materials, 45, 233-242.

[28] British Standards Institution, Fly ash for concrete. Definitions, specifications and conformity criteria, BS EN 450-1:2005 + A1:2007.

[29] Fernández-Jiménez, A., \& Palomo, A. (2003). Characterisation of fly ashes. Potential reactivity as alkaline cements 弥. Fuel, 82(18), 2259-2265.

[30] Kumar, R., Kumar, S., \& Mehrotra, S. P. (2007). Towards sustainable solutions for fly ash through mechanical activation. Resources, Conservation and Recycling, 52(2), 157-179.

[31] Escalante-García, J. I., Fuentes, A. F., Gorokhovsky, A., Fraire-Luna, P. E., \& Mendoza-Suarez, G. (2003). Hydration Products and Reactivity of Blast-Furnace Slag Activated by Various Alkalis. Journal of the American Ceramic Society, 86(12), 2148-2153.

[32] Richardson, I. G., Brough, A. R., Groves, G. W., \& Dobson, C. M. (1994). The characterization of hardened alkali-activated blast-furnace slag pastes and the nature of the calcium silicate hydrate (CSH) phase. Cement and Concrete Research, 24(5), 813-829.

[33] Ismail, I. (2013). Durability as a function of microstructure of alkali-activated slag/fly ash binders, PhD thesis, University of Melbourne.

[34] Richardson, I. G. (1999). The nature of CSH in hardened cements. cement and concrete research, 29(8), 1131-1147.

[35] Provis, J. L. (2014). Geopolymers and other alkali activated materials: why, how, and what? Materials and structures, $47(1-2), 11-25$.

[36] Yip, C. K., Lukey, G. C., \& Van Deventer, J. S. J. (2005). The coexistence of geopolymeric gel and calcium silicate hydrate at the early stage of alkaline activation. Cement and Concrete Research, 35(9), 1688-1697. 
[37] Garcia-Lodeiro, I., Palomo, A., Fernández-Jiménez, A., \& Macphee, D. E. (2011). Compatibility studies 608 between NASH and CASH gels. Study in the ternary diagram $\mathrm{Na}_{2} \mathrm{O}-\mathrm{CaO}-\mathrm{Al}_{2} \mathrm{O}_{3}-\mathrm{SiO}_{2}-\mathrm{H}_{2} \mathrm{O}$. Cement and 609 Concrete Research, 41(9), 923-931. 